University of Louisville

ThinkIR: The University of Louisville's Institutional Repository

Electronic Theses and Dissertations

8-2016

\title{
Global and specific attachment patterns in romantic relationships : distinct and interactional functions.
}

Megan Manthos

Follow this and additional works at: https://ir.library.louisville.edu/etd

Part of the Counseling Psychology Commons

\section{Recommended Citation}

Manthos, Megan, "Global and specific attachment patterns in romantic relationships : distinct and interactional functions." (2016). Electronic Theses and Dissertations. Paper 2554.

https://doi.org/10.18297/etd/2554

This Doctoral Dissertation is brought to you for free and open access by ThinkIR: The University of Louisville's Institutional Repository. It has been accepted for inclusion in Electronic Theses and Dissertations by an authorized administrator of ThinkIR: The University of Louisville's Institutional Repository. This title appears here courtesy of the author, who has retained all other copyrights. For more information, please contact thinkir@louisville.edu. 


\title{
GLOBAL AND SPECIFIC ATTACHMENT PATTERNS IN ROMANTIC RELATIONSHIPS: DISTINCT AND INTERACTIONAL FUNCTIONS
}

\author{
By \\ Megan Manthos \\ B.S., University of Washington, 2008 \\ M.Ed., University of Louisville, 2013 \\ A Dissertation \\ Submitted to the Faculty of the \\ College of Education and Human Development of the University of Louisville \\ in Partial Fulfillment of the Requirements \\ for the Degree of
}

Doctor of Philosophy in Counseling and Personnel Services

Department of Educational and Counseling Psychology,

Counseling, and College Student Personnel

University of Louisville

Louisville, Kentucky

August 2016 



\title{
GLOBAL AND SPECIFIC ATTACHMENT PATTERNS IN ROMANTIC RELATIONSHIPS: DISTINCT AND INTERACTIONAL FUNCTIONS
}

\author{
By \\ Megan Manthos \\ B.S., University of Washington, 2008 \\ M.Ed., University of Louisville, 2013 \\ A Dissertation Approved on
}

July 15, 2016

By the Following Dissertation Committee:

Jesse Owen, Ph.D.

Patrick Pössel, Dr. rer. soc.

Laurie "Lali" McCubbin, Ph.D.

Brad Shuck, Ed.D.
(Co-Chair)

(Co-Chair)

(Member)

(Member) 


\section{ACKNOWLEDGMENTS}

Dr. Jesse Owen, to whom I am grateful not only for his support for the duration of this research project, but for everything he has done to nurture my development as a researcher and psychotherapist over the past 6 years. To him, I owe my career.

My dissertation committee for their patience, good humor, and mentorship.

Dr. Kelley Quick and Dr. Jon Moore for emotional and statistical reinforcement.

My parents for their unceasing and unconditional love, support, and encouragement.

To women in science, everywhere. 


\begin{abstract}
GLOBAL AND SPECIFIC ATTACHMENT PATTERNS IN ROMANTIC RELATIONSHIPS: DISTINCT AND INTERACTIONAL FUNCTIONS
\end{abstract}

\author{
Megan Manthos
}

July 15,2016

Attachment theory conceptualizes emotional regulation and relational behavior as developmental processes grounded in early relationships with caregivers. Attachment has been researched extensively, however, there is not consensus about the mechanism of attachment across different relationship types (e.g., friends, family, romantic partners). Research suggests that attachment can be organized as an overarching global pattern of relating under which relationship-specific patterns emerge and vary distinctly. This study seeks to better understand the nature of global attachment patterns vs. romantic attachment patterns using self-report responses from a sample of 302 adults in serious romantic relationships. We hypothesized that psychological outcomes more referential to the self (self-esteem and psychological wellbeing) would be related to global attachment while outcomes more referential to relationships (dyadic coping and sexual satisfaction) would be related to romantic attachment. We also hypothesized that some outcomes reflecting a complex interaction of self- and relational-relevant dynamics (relationship commitment) may be related to an interaction of global and romantic attachment. Results supported the concept that global and romantic attachment patterns are related but distinct mechanisms. Insecure global attachment was negatively related to self-esteem (more so 
than insecure romantic attachment), wellbeing, and dyadic coping. Insecure romantic attachment was negatively related to all study outcomes, more than insecure global attachment for dyadic coping, sexual satisfaction, and relationship commitment. No interaction effects were found. These study results are consistent with a model in which attachment patterns vary based on relationship type and are also differentially related to fundamental individual and relational outcomes. Future research further elucidating this model and exploring the potential for attachment pattern repair is encouraged. Further implications and future directions are discussed. 


\section{TABLE OF CONTENTS}

ACKNOWLEDGMENTS .................................................................................

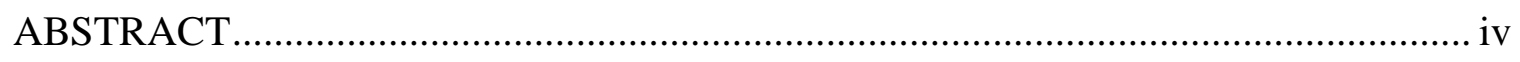

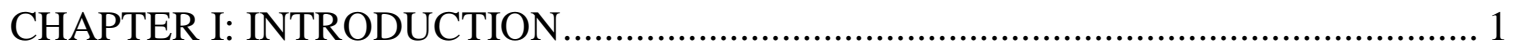

Attachment Theory and Attachment Patterns ...................................................... 1

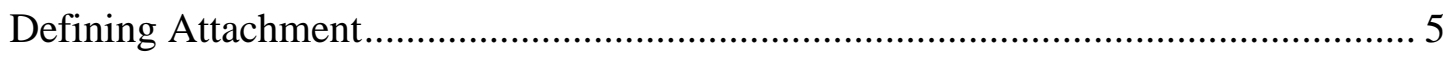

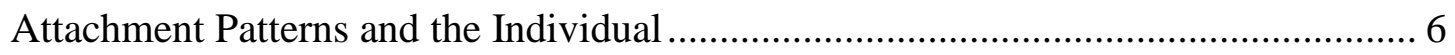

Attachment Patterns in Romantic Relationships................................................... 7

Stability of Attachment Patterns Across Time...................................................... 11

Consistency of Attachment Patterns Across Relationships .................................... 12

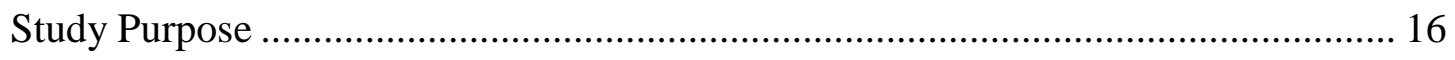

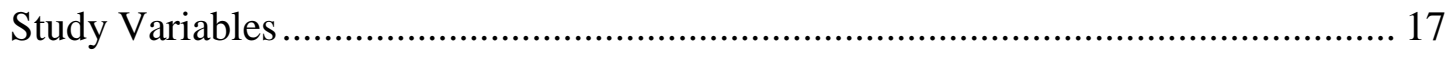

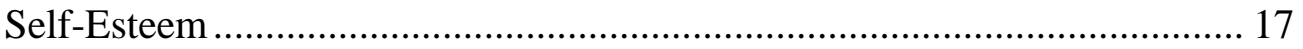

Psychological Wellbeing .............................................................. 18

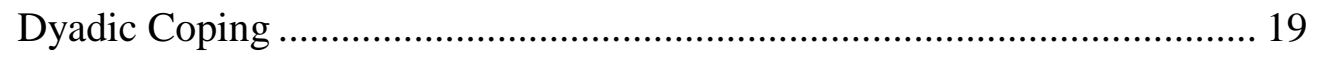

Sexual Satisfaction........................................................................ 20

Relationship Commitment ............................................................. 21 


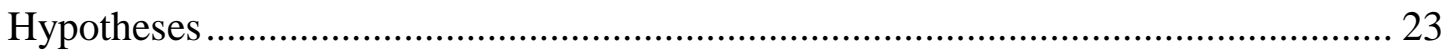

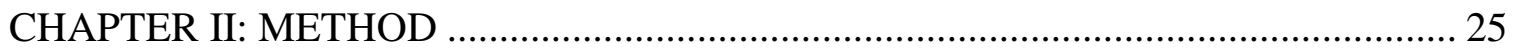

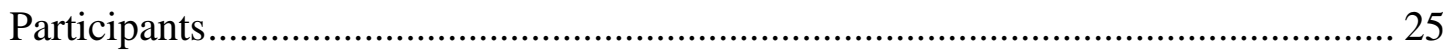

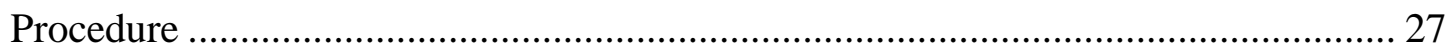

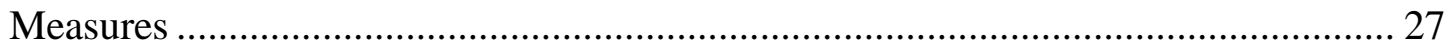

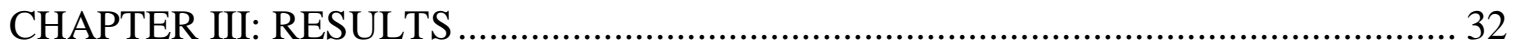

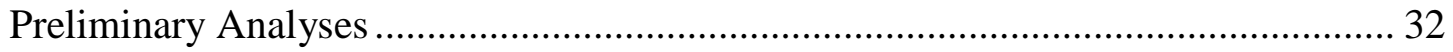

Table 1: Bivariate Correlations, Means, Standard Deviations, and Ranges ............... 34

Table 2: Bivariate Correlations for Demographic Variables and Outcomes .............. 35

Table 3: Tests of Difference ${ }^{\dagger}$ Between Correlates of Global and Romantic

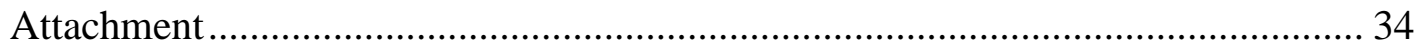

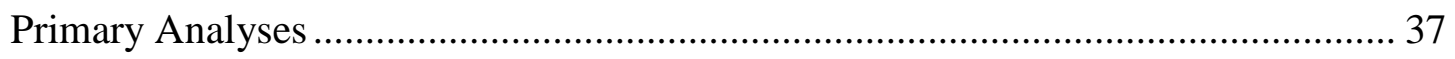

Hypothesis 1: Self Esteem ............................................................. 37

Hypothesis 2: Psychological Wellbeing …........................................... 38

Hypothesis 3: Dyadic Coping ......................................................... 38

Hypothesis 4: Sexual Satisfaction..................................................... 39

Hypothesis 5: Relationship Commitment ............................................ 40

Hypothesis 6: Additional Interactions ............................................. 41

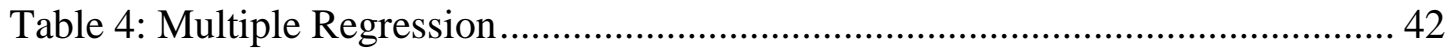

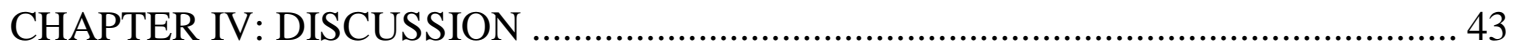


Limitations

Implications and Future Directions ............................................................ 50

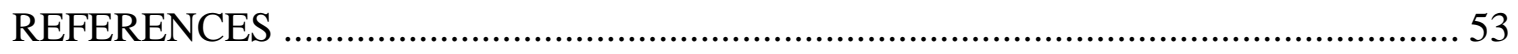

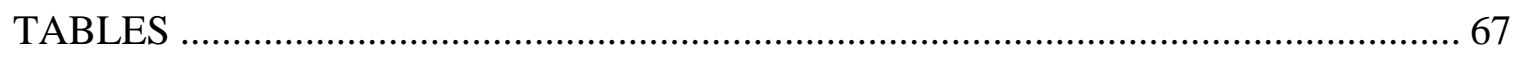

Table 1: Bivariate Correlations, Means, Standard Deviations, and Ranges ............... 67

Table 2: Bivariate Correlations for Demographic Variables and Outcomes .............. 68

Table 3: Tests of Difference ${ }^{\dagger}$ Between Correlates of Global and Romantic

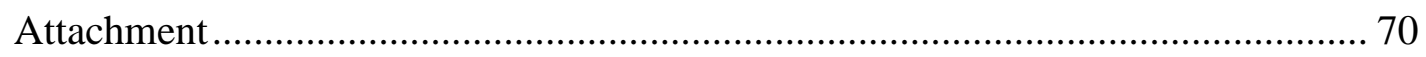

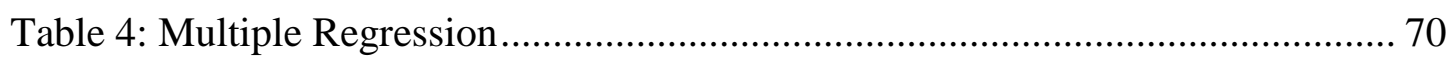

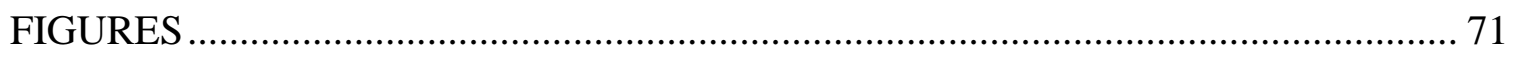

Figure 1: Attachment activation (Mikulincer et al., 2003) ..................................... 71

Figure 2: Potential Global x Romantic Interaction Effects ................................... 72

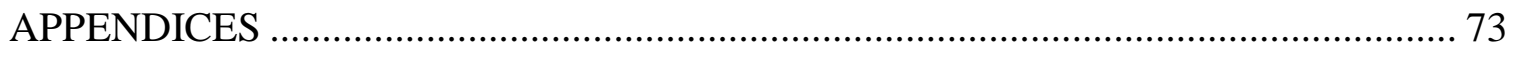

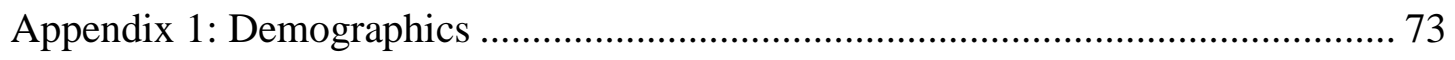

Appendix 2: Experiences in Close Relationships Scale - Short Form ..................... 74

Appendix 3: Rosenberg Self-Esteem Scale …................................................... 77

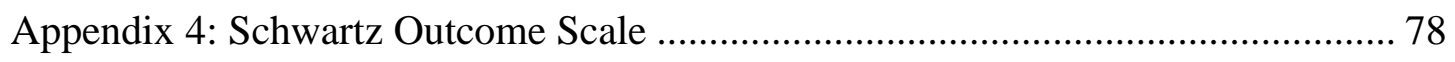

Appendix 5: Dyadic Coping Inventory …....................................................... 79

Appendix 6: Global Measure of Sexual Satisfaction ........................................... 81

Appendix 7: Revised Commitment Inventory .............................................. 82 
CURRICULUM VITAE. 


\section{CHAPTER I: INTRODUCTION}

Engaging in relationships with others is one of the lifelong joys of being human, and we are continually driven to establish intimate connections with those around us. The earliest of these relationships are with childhood caregivers (i.e., parents or other parental figures), with whom we develop our understanding of the process of interacting with others - relationships that are defined, ideally, by mutual caring and support. As we age, these supportive interactions expand to include acquaintances, friends, and romantic partners; relationships that are each defined by varying degrees of support, intimacy, and reciprocal dependence. Each of us has a unique way of attaching to intimate others defined by patterns of behavior and intrapsychic experience that are related to psychosocial and relational factors. This study seeks to explore how individual variations in these attachment patterns are related to individual and relational processes in the context of romantic relationships.

\section{Attachment Theory and Attachment Patterns}

In the psychological literature, attachment patterns are understood as manifestations of an internal working model that guides how people form and maintain intimate relationships (Fraley, Heffernan, Viacary, \& Brumbaugh, 2011a). These models can be conceptualized using attachment theory, which describes how individuals experience and behave in close relationships as a function of a learned pattern of attaching with others (Bowlby, 1969/1982). An extensive body of research using attachment theory has found links between attachment patterns in adults and numerous 
psychosocial outcomes, however, the vast majority of this research focuses on individual psychosocial outcomes and is based on measuring attachment as either 1) not relationship-specific or 2) applicable to a single relationship type, such as parents or romantic partners (cf. Overall, Girme, Lemay, \& Hammond, 2014; Zhang \& LabouvieVief, 2004). Less is known about how an individual's pattern of attachment across relationship types at a single time point may relate to the formation and maintenance of healthy romantic relationships.

Attachment theory was developed as a means of explaining the process of how early experiences with caregiving figures in infancy and childhood may shape how we interact in intimate relationships throughout the lifespan (Bowlby, 1969/1982). Ideally, early caregivers will provide a balance of care, supervision, and autonomy that enables a child to relate to others in a healthy way. This subsequent relational pattern is referred to as "secure attachment," which is characterized by the formation of stable bonds with others that occurs in a balance of three dichotomies: self vs. other (a cognitive dimension), autonomy vs. relatedness (an emotional dimension), and dependent vs. depended-on (a behavioral dimension) (Sochos, 2013). If early caregivers are neglectful, inconsistent, or imbalanced in their delivery of care, there is a risk that a child may develop an insecure attachment pattern. Insecure attachment patterns are typified by behaviors consistent with an imbalance across the three dimensions. Insecure attachment is conceptualized as avoidant attachment, in which the self, autonomy, and independence are overly emphasized; and anxious attachment, in which the other, relatedness, and dependence are overly emphasized. Avoidant attachment is characterized by an aversion to intimacy and overall dismissiveness in relationships, while anxious attachment is 
characterized by heightened relationship anxiety, fear of abandonment, and preoccupation with relationship dynamics (Creasy \& Jarvis, 2008). These categorizations are supported by Ainsworth et al.'s (1970) work with infant-mother attachment interactions and have been replicated in numerous subsequent studies (see Ravitz, Maunder, Hunter, Sthankiya, \& Lancee, 2010, for a review).

For all age groups, the general mechanism of attachment is the same: it is an affect regulation system wherein cognitive processes and proximity-seeking behaviors guide how we interact with others whose roles are to protect and/or comfort us in times of danger or stress. Mikulincer, Shaver, \& Pereg (2003) have defined a model of attachment activation and functioning that illustrates this process (Fig. 1).

Attachment needs are activated by a

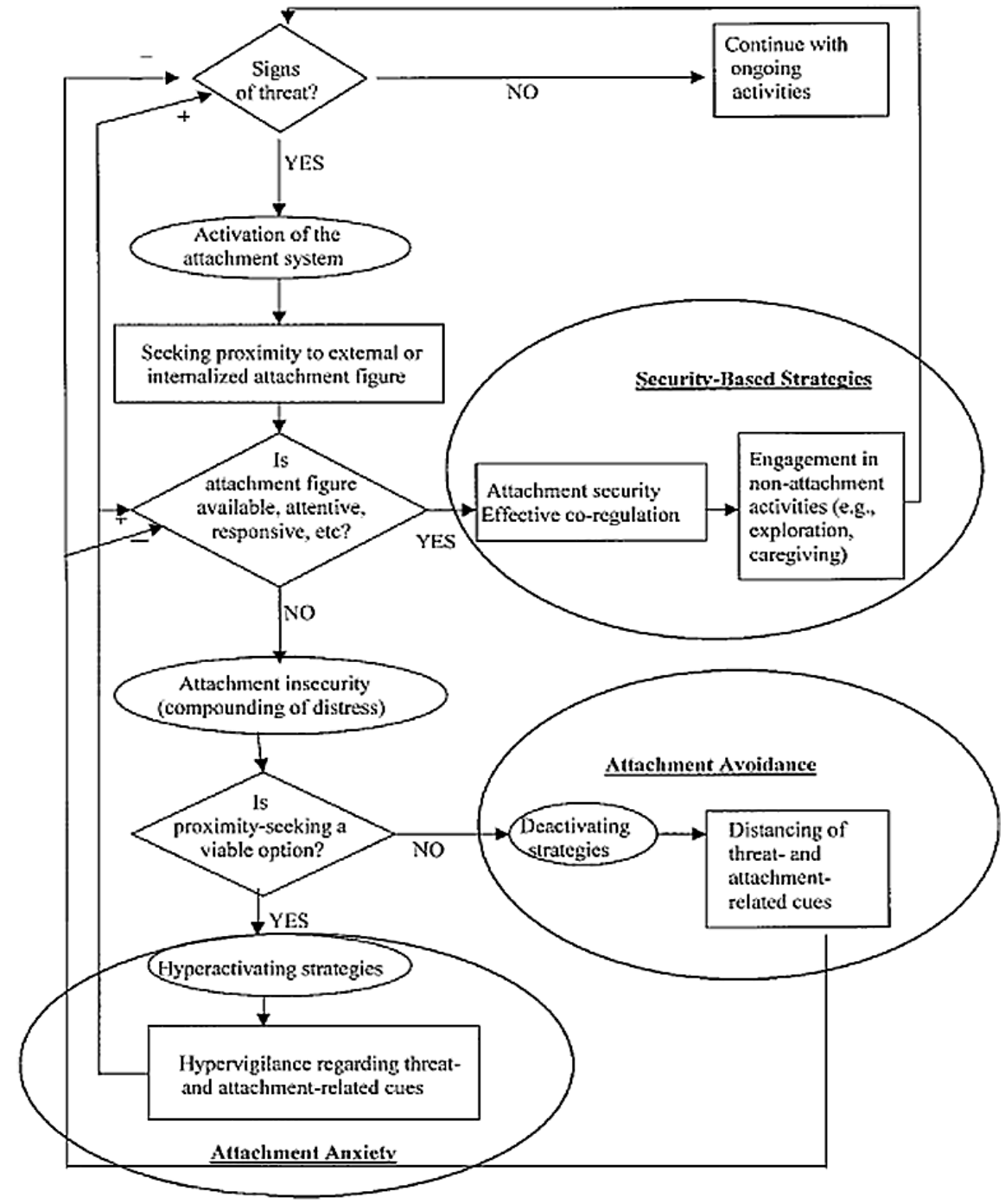

Figure 1: Attachment activation (Mikulincer et al., 2003) perceived sign of threat 
(broadly defined; threat can be as simple as encountering a novel situation in which one feels uncomfortable). Feeling threatened may prompt a person to seek out someone in their life who they conceptualize as protecting or comforting them in times of distress (i.e., an attachment figure). If that attachment figure is responsive in a manner that successfully activates feelings of safety or comfort, the person may experience positive affect, and their attachment security is reinforced. However, if the attachment figure is unavailable, unresponsive, or unsafe, the person may experience negative affect or an increase of distress. This takes them to a point of divergence: they respond with hyperactivation of proximity-seeking behaviors consistent with anxious attachment (e.g., pursuit of a response from the attachment figure) or deactivation of proximity-seeking consistent with avoidant attachment (e.g., withdrawal from the attachment figure). These patterns, repeated over time, reinforce the emerging attachment strategy (Mikulincer et al., 2003).

While attachment theory was developed primarily in reference to child-parent relationships, these same constructs have been found to be active across the lifespan (Paradiso, Naridze, \& Holm-Brown, 2011; Sroufe, 2005; Zhang \& Labouvie-Vief, 2004). A meta-analysis of over 2,000 adults and adolescents from studies conducted in the United States, Canada, United Kingdom, Australia, and the Netherlands ${ }^{1}$ yielded prevalence rates for attachment strategies as follows: 58\% secure, $24 \%$ avoidant, and 18\% anxious (van IJzendoorn \& Bakermans-Kranenburg, 1996).

\footnotetext{
${ }^{1}$ The geographic origins of these data are noteworthy, as the concept of attachment is of Western origin and may not be applicable to non-Western peoples without significant accommodations for cultural variation (Agishtein \& Brumbaugh, 2013).
} 


\section{$\underline{\text { Defining Attachment }}$}

Comparisons of methods used to study attachment show that there are significant inconsistencies in the measurement and operationalization of attachment patterns (Fraley et al., 2011a). These reflect differences in our understanding of the mechanism and function of attachment. For example, a romantic relationship is generally not expected to exactly mimic a caregiver-child relationship, particularly in terms of relational reciprocity - caregivers by nature have a disproportional responsibility for support, while romantic relationships are defined by balance of mutual dependence that varies based on the relational dynamic between the individuals involved. Stepping back to consider Bowlby's (1969/1982) original model of attachment patterns and broad uniformities in subsequent methodologies, attachment relationships are best defined as being with people we turn to in times of emotional need. The proximity-seeking behaviors observed by Ainsworth et al. (1970) in young children are replicated in adulthood not only by bids for physical closeness but also by seeking emotional reassurances irrespective of physical location. Based on foundational theory and operationalization by subsequent research, attachment relationships are those in which at least one person seeks reassurance (emotional safety) in a way that is central to how they relate to others in times of distress. The resulting interpersonal interaction in turn has some impact on the internal working model(s) of attachment of those involved. While the formation and maintenance of attachment strategies in early childhood has been well-studied, the nature of how attachment interactions in adulthood subsequently impact attachment strategies in individuals is not yet clear (e.g., Grossman, 1999; Overall, 2003). 
There are a few major models of attachment that are well-established and have been supported by years of research; these share an overarching concept of secure versus insecure attachment (see Ravitz, et al., 2010 for a review). The model we have chosen for this study defines insecure attachment as a function of either anxious or avoidant behaviors. There are substantial differences in how many individual and relational outcomes have been associated with anxious versus avoidant attachment patterns; however, both of these types of insecure attachment are associated with some major indicators of individual wellbeing and/or relationship quality similarly. Using the large amount of available data on attachment, we are able to examine anxious and avoidant attachment interactions using the single category of "insecure attachment" by thoughtfully selecting study variables for which the associations are predictably similar in direction despite potential differences in magnitude. For the purpose of this pilot study, we will take this approach in the hope that it will guide future research, which may benefit from the additional nuance detectable when insecure attachment is divided into subcategories.

\section{Attachment Patterns and the Individual}

Adult attachment patterns have been associated with numerous traits related to psychological and physical health and wellbeing, with an overall trend of insecure attachment being associated with poor outcomes. On a physiological level, insecure attachment has been associated with a more damaging and less resilient hormonal response to stress compared to secure attachment (Pierrehumber et al., 2013) and higher levels of disability and experience of pain (Forsythe et al, 2012). Higher levels of insecure attachment have also been associated with lower levels of perceived social 
support and higher levels of irritability (Kafetsios \& Sideridis, 2006); lower overall life satisfaction (Lavy \& Littman-Ovadia, 2011); lower subjective wellbeing (Wei, Liao, Ku, \& Shaffer, 2011); loneliness (Hazan \& Shaver, 1987; Kafetsios \& Sideridis, 2006) lower self-esteem (Feeney \& Noller, 1990), higher levels of anxiety (Kafetsios \& Sideridis, 2006; Mikelson, Kessler, \& Shaver, 1997), depression (Mikelson, Kessler, \& Shaver, 1997; Paradiso et al., 2011), and interpersonal problems (Wilhelmsson Göstas et al., 2012). In turn, secure attachment has been found to predict psychological wellbeing (Karreman \& Vingerhoets, 2012) and feelings of joy and interest in life (Consedine \& Fiori, 2009). It may be that attachment is a component of emotional regulation and/or resiliency to stress that serves a function in maintaining individual psychological wellbeing. It is important to note that attachment patterns are likely not a guaranteed determinant of healthy or unhealthy psychological wellbeing; rather, attachment patterns exist as an important component of a constellation of risk and protective factors (Sroufe, 2005).

\section{$\underline{\text { Attachment Patterns in Romantic Relationships }}$}

As we approach adulthood, our relationships with childhood caregiver(s) tend to recede into the background as we assign more importance to developing new friendships. Among these friendships, romantic relationships can be some of the most intimate and emotionally engaging - but are they attachment relationships? For many years after the concept of attachment pattern was introduced, it was studied primarily in the context of parent-child relationships. Hazan and Shaver (1987) were the first to examine attachment pattern as a component of adult romantic relationships, and their findings support the idea that attachment is relevant in these interactions. The results of their work indicate that 
adults display secure, avoidant, and anxious attachment patterns and that these patterns are associated with working models of self and other in romantic relationships as well as variation in the intrapsychic experience of love (e.g., the personal, internal experience of love). In keeping with the idea that attachment patterns are stable across the lifespan, this research also found that participants' romantic attachment patterns were consistent with their descriptions of their relationship with their childhood caregiver, a finding that was supported by subsequent research (e.g., Collins et al., 1990; Feeney \& Noller, 1990); including a variation of Ainsworth et al.'s (1970) Strange Situation study in which couple behaviors were observed and found to be congruent with previous categorizations of attachment patterns (Crowell et al., 2000). At this point, the idea that romantic relationships can be attachment relationships is well-supported and widely accepted.

What is the role of attachment pattern in romantic relationships? As outlined by Johnson, Makinen, and Millikin (2001), the enactment of attachment patterns between two romantic partners progressively impacts the reciprocal development of intimacy and trust in the relationship. Interactions that fail to fulfill the attachment needs of one or more partners contribute to a disintegration of relationship integrity. Similarly to what has been found in studies of attachment patterns in individuals, insecure attachment has also been associated with a number of negative outcomes in romantic relationships.

Insecure attachment has been associated with a tendency to interpret interactions with a partner as being more negative and less positive (Sadikaj et al., 2011; Wood et al., 2002). In accordance with this tendency, insecure attachment is consistently associated with lower levels of romantic relationship satisfaction and lower levels of relationship commitment, associations that tend to become stronger as relationships grow longer (see 
Hadden, Smith, \& Webster, 2014, for a meta-analysis). These associations illustrate the cognitive manifestation of attachment patterns in relationships. Insecure attachment is grounded in a pervasive inability to believe that intimacy is safe; this contributes to a perception of relational instability. People who report insecure attachment have been found to also report negative expectations about romantic love, such as the idea that it will inevitably fade over time (Hazan \& Shaver, 1987). Lacking trust that their relationship is stable enough to last, people who report higher levels of insecure attachment may find it difficult to commit to their partner. Relationship satisfaction may therefore be limited by perceptions of instability, a lack of safety in intimate relating, and a less positive outlook on the future.

Insecure attachment is also associated with lower levels of happiness in romantic relationships (Treboux, Crowell, \& Waters, 2004). Emotional experience is one differentiating factor between anxious and avoidant attachment patterns, as anxious attachment is related to heightened emotional experiencing and expression while the inverse is true for avoidant attachment (Ben-Naim, Hirschenberger, Ein-Dor, \& Mikulincer, 2014). These differences, however, seem to be related more to the manner in which people who report insecure attachment regulate emotion; as those with more anxious attachment tend to report overwhelming, exaggerated responses to negative emotions while those with avoidant attachment tend to minimize negative emotions and distance themselves from the experience of them. However, when latent (less overt) measures of emotional experience are used, the differences between the two attachment patterns lessen, supporting the idea that the emotional regulation systems associated with attachment patterns may mediate the association between poor relationship quality and 
subsequent negative emotions (see Shaver \& Mikulincer, 2002, for a review). Despite these differences, when compared with people who report secure attachment patterns, those who report avoidant or anxious attachment patterns both report significantly higher rates of negative emotions and significantly lower rates of positive emotions related to their relationships (Mikulincer et al., 2003; Treboux et al., 2004).

Given the above, it is not surprising that insecure attachment has also been linked to poor relationship maintenance behaviors and higher rates of relationship dissolution (see Mikulincer, Florian, Cowan, \& Cowan, 2002, for a review) as well as higher levels of physical and verbal aggression toward romantic partners (Miga et al., 2010) ineffective caregiving and support-seeking behavior (Collins \& Feeney, 2000), and infidelity (Beaulieu-Pelletier et al., 2011; Starks \& Parsons, 2014). These results may be indications that attachment behaviors designed to solicit caregiving responses from romantic partners, and/or behaviors subsequent to attachment needs not being met, may contribute to the escalation of conflict and/or mutual distancing behaviors. For example, a person enacting insecure attachment behaviors may withdraw from their partner or display heightened negative affect in the midst of what might otherwise be a reparative interaction (e.g., Overall et al., 2014).

As the above illustrates, insecure attachment has clearly and repeatedly been associated with lower individual wellbeing and numerous poor cognitive, emotional, and behavioral relationship outcomes - but what can be done about it? Are we doomed to repeat the same maladaptive patterns of interaction throughout the duration of a lifetime? In pursuit of an answer to this question, we must question both the stability/fluidity of attachment patterns across time and the consistency of attachment patterns across people. 


\section{$\underline{\text { Stability of Attachment Patterns Across Time }}$}

Attachment pattern has generally been considered to be stable across the lifespan, meaning that one person's attachment pattern remains unchanged over time. This theory, referred to as the prototype model, has garnered substantial support (e.g., Fraley, Vicary, Brumbaugh, \& Roisman, 2011b). However, a growing body of research suggests attachment patterns have the potential to fluctuate over time. A recent meta-analysis of longitudinal studies ranging from 6 months to 29 years resulted in a moderate correlation of attachment patterns from Time 1 to Time $2(r=.39,95 \%$ CI $[.35, .42], p<.001)$. Overall, stability of attachment patterns dropped significantly for intervals of more than five years and became nonsignificant at time intervals of 15 years or more (Pinquart, Feußner, \& Ahnert, 2012). These data support the idea that fluctuations in attachment patterns over the lifespan are the norm, rather than the exception. The experience of psychosocial stress seems to be a strong contributor to these fluctuations. Even those for whom attachment patterns are characterized by overall long-term stability, significant short-term fluctuations in attachment patterns may occur related to the occurrence of stressful events and changes in wellbeing and coping (e.g., Waters, Merrick, Treboux et al., Crowell, \& Albersheim, 2000; Zhang \& Labouvie-Vief, 2004). Attachment patterns may be related in some way to changes in psychosocial variables that have the potential to fluctuate across the lifespan. If stressful experiences have the potential to impact attachment patterns, it could be that relational stressors (such as conflict and lack of support behaviors) play a role in attachment patterns in relationships, resulting in a modification of attachment patterns that directly relate to a specific relationship and could therefore, theoretically, change based on the nature of that relationship. 


\section{Consistency of Attachment Patterns Across Relationships}

Historically, attachment patterns have also been studied as if they are consistent across relationship types (e.g., parent, partner, friend). Over the past 15 years, however, there has been increasing empirical support for the possibility that some people may exhibit attachment differentially in their various relationships. In contrast to the traditional conceptualization of attachment pattern as a stable personality trait, numerous studies have found that attachment pattern may be viewed in terms of relationshipspecific models (Caron, Lafontaine, Bureau, Lesvesque, \& Johnson, 2012; Pierce \& Lydon, 2001; Sibley \& Overall, 2007). Present-day understanding has evolved to a general consensus that recognizes an overall trend of homogeneity of attachment patterns across relationship types that yields pairwise comparisons between attachments to early caregivers, romantic partners, and close friends that are broad in range and small-tomoderate overall $(.09 \leq r \leq .55$; Fraley et al., 2011a; Klohnen et al., 2005; Laguardia et al., 2000; Mehta et al., 2009). To explain these findings, several models have been developed to illustrate attachment as a multipart system. These typically involve a set of relationship-type-specific attachment patterns that exist in conjunction with a global attachment pattern representing a generalized working model that guides attachment across relationships. For example, Overall et al. (2003) tested three models representing the most common conceptualizations of attachment across relationships (first, a model of one single attachment pattern governing all relationships; second, a model with 3 independent attachment patterns governing relations with family, friends, and romantic partners; third, a model with an overarching global attachment pattern governing a subset

of attachment patterns for family, friends, and romantic partners). Results supported the 
third model (CFIs >.97, RMSEAs <.07), suggesting that attachment in adulthood manifests as differentiated patterns across relationship types that are linked by an overarching global attachment pattern impacting each relationship. Subsequent research has provided additional support for this model (e.g., Treboux et al., 2004) and, more recently, has resulted in theorizing that global and specific patterns of attachment may even have distinct developmental paths of origin (Haydon et al, 2012). Global attachment patterns may be related more strongly to attachment relationships with early caregivers while specific relationship types factor more strongly into specific attachment patterns.

Comparisons of individuals' global attachment pattern to their romantic attachment pattern reveal that at any one time, approximately one-third to one-half of participants report romantic attachment patterns that differ from their global attachment pattern (Creasey et al., 2005; Treboux et al., 2004). Patterns of this differentiation have been also associated with differing sets of thoughts, feelings, and behaviors in couple relationships. For example, in a 6-year longitudinal study of 258 couples, Treboux et al. (2004) found that different combinations of insecure/secure global attachment with insecure/secure romantic attachment were associated with significantly different patterns of secure base behavior (such as support-seeking), relationship conflict, and positive feelings in romantic relationships - moreover, these patterns were differentially associated with the experience of psychosocial stressors. Not surprisingly, the group reporting secure global and secure romantic attachment patterns also reported the most positive relational outcomes; while the group reporting insecure global and insecure romantic attachment patterns reported numerous negative relational outcomes. However, there were unexpected results from the groups reporting differentiated attachment 
patterns. Individuals in the secure global/insecure romantic group were significantly more likely to separate or divorce and were the most distressed group overall. This group was also the most sensitive to the occurrence of negative life events, which resulted in a sharp increase in relationship conflict and corresponding decrease in positive feelings about the relationship. The insecure global/secure romantic group, however, reported overall relational patterns similar to the secure/secure group and demonstrated less sensitivity to negative life events when compared to the secure global/insecure romantic group. These results suggest that not only are attachment pattern discrepancies related to relationship outcomes, but the nature of the discrepancy itself may also be important to couple functioning.

It may be that the internal working models associated with global and specific attachment patterns serve different functions in the context of a single relationship. In an exploration of this theory, Cozzarelli, Hoekstra, and Bylsma (2000) found that global attachment was more strongly associated with individual psychosocial variables (e.g., wellbeing) while romantic attachment was more strongly associated with relational outcomes (e.g., relationship satisfaction). If this is the case, any given interaction within a relationship may be guided more by an individual's global or romantic attachment pattern based on the extent to which the interaction involves individual vs. relational factors. These factors do not, however, exist within a vacuum. Attachment patterns manifest within relationships as systemic factors that exist in a continual interaction with other individual and relational variables (as proposed by Mikulincer, Florian, Cowan, \& Cowan, 2002). If global and romantic attachment patterns do serve specific and separate functions, it seems likely that the associated internal working models are active based on 
the degree to which the function is relevant to individual vs. relational outcomes. For outcomes that are highly relevant to both individual and relational functioning, however, both global and specific attachment systems may be active and may therefore interact to produce unique patterns of relating to a partner. Theoretically, a person enters into a romantic relationship with extant characteristics that are predetermined by historical or individual factors which, in turn, interact with dynamics relevant to the new relationship. In terms of attachment, this fits with the proposition that global attachment precedes romantic attachment either developmentally/chronologically (Haydon et al, 2012) or as an overarching component of a more complex attachment system (Overall, 2003). If this is the case, global attachment may represent the larger set of prior experiences that set a person's expectations for attachment interactions as they enter into a romantic relationship (Cozzarelli et al., 2000; Haydon et al., 2012; Treboux et al., 2004). Attachment-relevant thoughts, feelings, and behaviors in a romantic relationship may therefore occur as an interaction between these expectations and the current attachment interactions of the relationship. Taking into account the theories discussed thus far related to the developmental trajectory and/or hierarchy of global vs. romantic attachment patterns, it seems that global attachment may moderate the relationship between romantic attachment and various individual and relational outcomes and vice versa. As global attachment is more secure, the relationships between insecure romantic attachment and 
some outcomes may be stronger (i.e., more relevant as being either congruent or in contrast to global

expectations). As

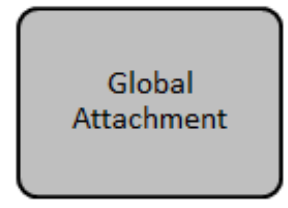

romantic attachment is

more secure, the

relationships between
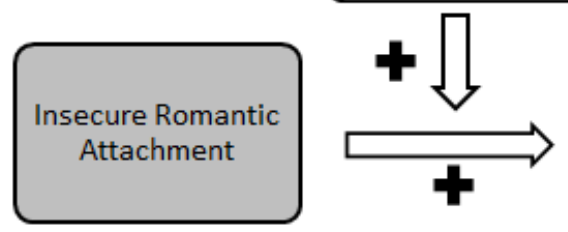

Relational Variable

(e.g., Relationship Committment)

insecure global

Secure Global Attachment may amplify Insecure Romantic Attachment.

attachment and some

outcomes may be

weaker (i.e., secure

romantic attachment

acting as a reparative

factor). See Fig. 2 for an

illustration of these
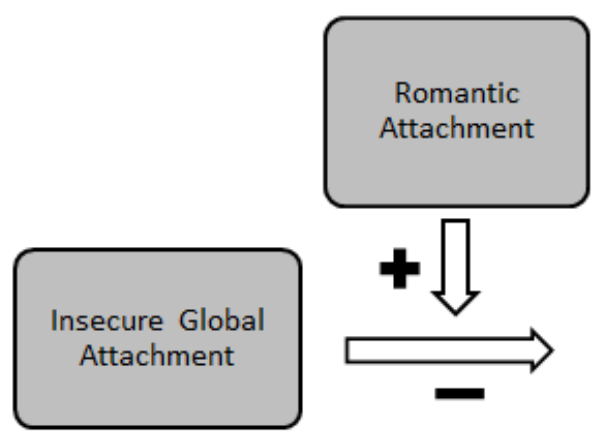

Individual Variable

(e.g., Self-Esteem)

Secure Romantic Attachment may lessen Insecure Global Attachment.

possibilities.

Figure 2: Potential Global x Romantic Interaction Effects

\section{$\underline{\text { Study Purpose }}$}

This study seeks to examine the roles of global and specific attachment patterns in the context of romantic relationships. In doing so, we hope to (a) explore the possibility of differentiation between the roles of global and specific attachment patterns in these processes based on the degree to which the process references the self vs. the relationship; and (b) explore the possibility of interaction between global and specific attachment patterns contributing to variation of individual and relational outcomes. To do 
so, we have selected a set of variables that are categorized as more individual or more relational.

\section{$\underline{\text { Study Variables }}$}

\section{Self-Esteem}

"Self-esteem" is used to refer to a person's overall sense of worth, which is thought to reflect both (a) self-evaluation of personal characteristics and (b) perceptions and valuing of how one is viewed by others (Rosenberg, Schooler, Schoenbach, \& Rosenberg, 1995). Self-esteem is a personality trait that is believed to be universal across cultures (Schmitt \& Allik, 2005). In adulthood, self-esteem is considered to be stable overall. While minor fluctuations in self-esteem occur throughout the lifespan, these are much less common after age 30 and typically reflect self-esteem in reference to specific attributes of the self (e.g., physical attractiveness) as opposed to global self-esteem (Huang, 2010).

Attachment pattern by definition is a relational trait that has been linked to numerous individual outcomes (as described above). In theory, if there is differentiation in the degree to which global vs. romantic attachment patterns govern individual vs. relational outcomes, this may be in relation to the degree to which the characteristic is referential to the global self as opposed to a specific relationship. Self-esteem is a highly self-referential trait that has a relational component in the sense that it may be impacted by our feelings about how others perceive us. We would therefore expect romantic attachment pattern to play a role in self-esteem, and indeed it has been found that insecure romantic attachment patterns are associated with lower self-esteem (Cozzarelli et al., 2000; Schmitt \& Allik, 2005). However, lower self-esteem has also been related to 
global insecure attachment (Foster, Kernis, \& Goldman, 2007) and insecure attachment to peers (Gorrese \& Ruggieri, 2013) and early caregivers (Gomez \& McLaren, 2007). This makes sense in the context of our understanding that attachment patterns manifest developmentally before self-esteem (Bylsma, Cozzarelli, \& Sumer, 1997) and may therefore play a role in the process of self-actualization, which is strongly linked to selfesteem (Otway \& Carnelley, 2013). These findings are in line with the idea that selfesteem is not linked to a specific relationship type but is a more global phenomenon. Psychological Wellbeing

"Psychological wellbeing" refers to one's generalized satisfaction with self and life in the absence of psychological distress, and it is used as a broad construct reflecting overall psychological health and functioning (Blais, 2012). While psychological wellbeing and self-esteem are frequently linked, correlations between the two generally support the assertion that they are distinct constructs (e.g., $-.23<r<.50$; Rosenberg, Schoenbach, Schooler, \& Rosenberg, 1995), and a growing body of research suggests that the link between self-esteem and psychological wellbeing varies widely across cultures (Spencer-Rodgers, Peng, Wang, \& Hou, 2004). Psychological wellbeing encompasses a wide range of an individual's internal and external experiencing. Insecure attachment and psychological wellbeing have been consistently found to have an inverse relationship to the extent that those who report insecure attachment are significantly more likely to suffer from clinical disorders related to depression, anxiety, and personality disorders (Mikelson, Kessler, \& Shaver, 1997). The relationship between attachment patterns and psychological wellbeing is complex, and a constellation of variables have been found to play a mediating role between the two (empathy and self-compassion, Wei, 
Liao, Ku, \& Shaffer, 2011; love, hope, gratitude, curiosity, perspective, and zest, Lavy \& Littman-Ovadia, 2011; social support, Kafetsios \& Sideridis, 2006; satisfaction of basic psychological needs, Wei, Shaffer, Young, \& Zakalik, 2005). Regardless of the mechanism involved, insecure attachment is consistently associated with lower levels of psychological wellbeing (see also Cozzarelli et al., 2000). It seems that attachment patterns reflect variation in the way people think, feel, and behave in a manner that may be continually relevant to their experience of the world. Because this relationship seems to go beyond any one relationship, we expect psychological wellbeing to be related to global attachment.

Dyadic Coping

"Dyadic coping" refers to the manner in which a person engages in reciprocal support behaviors with a partner in response to stress (Meuwly, Bodenmann, Germann, Bradbury, Ditzen, \& Heinrichs, 2012). Positive dyadic coping has been related to numerous good relationship outcomes, including higher marital satisfaction and reduced negative impacts of stress on relational functioning (Landis, Peter-Wright, Martin, \& Bodenmann, 2013; Meuwly et al, 2012). While dyadic coping is a dynamic process that occurs between members of a couple, individuals exhibit a personal style of coping in the context of partner interactions (Bodenmann, Meuwly, \& Kayser, 2011). Individual dyadic coping has been found to contribute uniquely to positive relational functioning and increased supportive behaviors in partners (Papp \& Witt, 2010). Bodenmann et al. (2011) found that dyadic coping was more strongly associated with relationship quality than individual psychological wellbeing, which supports the idea that it is a primarily relational variable. 
Because dyadic coping reflects style of relating to a partner in a time of stress, attachment patterns are highly relevant in these interactions. When called upon to engage in reciprocal support behaviors, a person with an insecure attachment pattern is more likely to withdraw or become disengaged, react with disproportionately high or low emotion, approach their partner with lower feelings of trust (Fuenfhausen \& Cashwell, 2013), and interpret their partner's statements more negatively (Gallo \& Smith, 2001). Not surprisingly, dyadic coping has been inversely linked with insecure attachment (Fuenfhausen \& Cashwell, 2013). Because this variable reflects an active in-the-moment relational process, we anticipate that dyadic coping will be associated strongly with romantic attachment.

\section{Sexual Satisfaction}

In the context of this study, "sexual satisfaction" refers to an individual's general, overall subjective assessment of their own sexual fulfillment in their relationship (Lawrence \& Byers, 1998). Insecure attachment has consistently been associated with lower sexual satisfaction for both self and partner (Brassard, Péloquin, Dupuy, Wright, \& Shaver, 2012; Birnbaum, 2007; Butzer \& Campbell, 2008). People who enact avoidant attachment patterns may feel discomfort or aversion related to the intimacy and affection inherent in some sexual activities, while those who enact anxious attachment patterns may find that intense feelings of need for intimacy and closeness overwhelms other potentially positive elements of their sexual experience (Birnbaum, Reis, Mikulincer, Gillath, \& Orpaz, 2006). Both anxious and avoidant attachment patterns have been associated with lower rates of intimacy, arousal, and orgasms with a partner (in women; Birnbaum, 2008; Cohen \& Veltsky, 2008). The extant research on attachment and 
sexuality suggests that attachment patterns manifest in sexual interactions similarly to other intimate ways of engaging (see Birnbaum, 2010, for a review). Similar to dyadic coping, sexual satisfaction in the context of a romantic relationship is an indicator for a complex interaction that occurs between two people. Because it is an inherently relational process, we anticipate that sexual satisfaction will be related to romantic attachment.

\section{Relationship Commitment}

"Relationship commitment" refers to the degree to which a person in a relationship has (1) a sense of couple identity and (2) a sense of that couple identity continuing into the future (Stanley, Rhoades, \& Whitton, 2010). While various models of commitment in relationships exist, one that has garnered substantial support defines two types of commitment: dedication commitment, which refers to emotional investment in a partner (e.g., feelings of love); and constraint commitment, which refers to material investment in a partner (e.g., owning a house together) (Stanley \& Markman, 1992). For the purpose of this paper, we will use the term "commitment" to refer to dedication commitment, which more closely aligns with the traditional idea of romantic closeness with a partner (Stanley et al., 2010). Higher levels of commitment to a romantic relationship are associated with numerous positive outcomes, including relationship satisfaction and lower feelings of being trapped (Stanley, Markman, \& Whitton, 2002). Lower levels of commitment are, unsurprisingly, related to higher likelihood of leaving a partner (see Le \& Agnew, 2003 for a review). Avoidant attachment patterns have been consistently associated with lower levels of commitment, which may be seen as a threat to the high need for autonomy associated with avoidant attachment (Birnie, McClure, Lydon, \& Holmberg, 2009; Etcheverry, Le, Wu, \& Wei, 2013; Hadden et al., 2014). The 
relationship between anxious attachment patterns and commitment seems to be more complex. While anxious attachment patterns tend to involve a strong desire for connection, reassurance, and relational maintenance; these are accompanied by intense and persistent fears of relational dissolution and difficulty trusting relational stability (Tran \& Simpson, 2009). Research examining anxious attachment and commitment has yielded mixed findings with some support for the idea that anxious attachment drives relationship persistence (Slotter \& Finkel, 2009). However, there seems to be more support for the idea that the high levels of emotional volatility associated with anxious attachment patterns may undermine commitment (e.g., Etcheverry et al., 2013; Hadden et al., 2014). In turn, higher levels of commitment have been associated with lower feelings of relational insecurity in participants reporting anxious attachment patterns, suggesting that feelings of commitment may help to buffer the relationship between anxious attachment and relational anxiety (Tran \& Simpson, 2009).

In summary, it would seem that both types of insecure attachment are likely related to lower levels of commitment - but is this guided more by global or romantic attachment patterns? While relationship commitment has clear links to relational functioning, it also represents an individual approach or stance taken by one partner in relationship. The degree to which this variable is individual vs. relational is less clear than our other outcomes. We therefore anticipated that this outcome is related to an interaction of attachment patterns, specifically, that global attachment pattern would moderate the relationship between romantic attachment pattern and relationship commitment. 


\section{$\underline{\text { Hypotheses }}$}

1. There will be a main effect of global attachment style for self-esteem in the form of a negative relationship between self-esteem and insecure global attachment.

2. There will be a main effect of global attachment style for psychological wellbeing in the form of a negative relationship between psychological wellbeing and insecure global attachment.

3. There will be a main effect of romantic attachment style for dyadic coping in the form of a negative relationship between dyadic coping and insecure romantic attachment.

4. There will be a main effect of romantic attachment style for sexual satisfaction in the form of a negative relationship between sexual satisfaction and insecure romantic attachment.

5. There will an interaction of global and romantic attachment patterns for relationship commitment. Global attachment will moderate the relationship between romantic attachment and relationship commitment. As global attachment is less insecure/more secure, the relationship between romantic attachment and relationship commitment will grow stronger.

6. Given that little is known about the potential for interaction between global and romantic attachment, we will also examine the possibility for significant interaction across all other study variables as follows: (a) As global attachment is less insecure/more secure, the relationship between insecure global attachment and the individual variables (self-esteem and psychological wellbeing) will be stronger; (b) As romantic attachment is less insecure/more secure, the relationship between 
insecure global attachment and the relational variables (dyadic coping, sexual satisfaction) will be weaker. 


\section{CHAPTER II: METHOD}

\section{$\underline{\text { Participants }}$}

A power analysis was conducted in order to determine an appropriate sample size goal. Using effect size figures from previous research and in consideration of the scope of the current study, we anticipated finding medium effect sizes in the hypothesized relationships for each of the main effects specified above. In accordance with Cohen (1992), we determined that we would need 152 participants to detect a medium effect size $(d \geq .50)$ with a power level of $80 \%$ and a criteria for statistical significance of $\alpha=$ .05 . There is less previous work to inform our expectations for the interaction. Aiken \& West (1991) suggest that a reduction of up to $50 \%$ of power is typical when interaction effects are introduced into an analysis.

Recruitment was conducted using various online sources including websites for volunteer recruitment (e.g., craigslist.org), and social media (e.g., facebook.com). Study participants were adults aged 18 or over who completed consent procedures. There were no other exclusion criteria. All recruitment materials and procedures were IRB-approved.

Four hundred and seventy-eight (478) participants completed the consent process and indicated that they wanted to participate in the study. Of those participants, 105 indicated that they were not in a relationship or categorized their relationship as being casual and were therefore removed from the data set. An additional 65 participants were removed from the data set for various reasons related to data integrity (e.g., not answering the validity check correctly, having significant amounts of unanswered 
questions). Six (6) extreme scores (defined as $>3.5$ standard deviations away from the mean) were also removed - one participant with extreme scores on both the self-esteem and wellbeing scales, two more from the wellbeing scale, one from the dyadic coping scale, and two from the relationship commitment scale. The remaining sample of 302 participants comprised the final study sample. This exceeds the minimum 152 participants suggested by the power analysis as adequate for the study analyses.

Among the final sample, $31.5 \%$ of participants reported being in their current relationship for over 10 years, $25.8 \%$ for $5-10$ years, $11.2 \%$ for $3-5$ years, and $31.5 \%$ for less than 3 years. $83.1 \%$ of participants described their relational agreement as "Closed (my partner and I have agreed that we can NOT see other people)," while the remainder reported some variation of non-monogamy (e.g., "Open/Poly," "[partner] has had affairs"). In terms of gender, $77.8 \%$ of the sample identified as female, $19.2 \%$ identified as male, and 3\% identified as transgender, genderqueer, or nonbinary. In terms of sexual identity, $65.9 \%$ identified as heterosexual, $10.9 \%$ identified as bisexual, $6.6 \%$ identified as gay/lesbian, $3.9 \%$ identified as queer, $3.3 \%$ identified as pansexual, and the remaining 9.4\% reported other answers (e.g., "hetero-fluid," "homoflexible"). In terms of economic status, $18.9 \%$ reported a personal annual income of less than $\$ 20 \mathrm{k}, 31.5 \%$ reported $\$ 20$ $\$ 50 \mathrm{k}, 23.8 \%$ reported $\$ 50-\$ 75 \mathrm{k}, 10.9 \%$ reported $\$ 75-\$ 100 \mathrm{k}, 13.6 \%$ reported over $\$ 100 \mathrm{k}$, and $1.7 \%$ declined to answer. In terms of education, $4 \%$ reported some high school, 21.2\% had some college, $35.4 \%$ had a 4 -year degree, $29.1 \%$ had a masters-level degree, and $10.3 \%$ had a doctoral-level degree. In terms of racial/ethnic identity, $81.5 \%$ identified as White, 5.3\% identified as Asian/Pacific Islander, 2.6\% identified as Hispanic, 1.6\% identified as Black, and the remaining $9 \%$ reported another race/ethnicity (e.g., 
"multiracial," "Mixed Native American and Caucasian," "human"). Participants ranged from 18 to 71 years old (Median $=34, \mathrm{SD}=9.2$ years).

\section{Procedure}

All study data were collected in April of 2015 using an online survey hosted by qualtrics.com, a secure online survey platform. Participants were first asked to read a consent form describing the study and study participants' rights. If they did not agree to participate, they exited the survey on their own or clicked a button that redirected them to a screen thanking them for considering participation. If they agreed to participate in the study, clicked a button to proceed to the survey.

At the end of the survey, participants were thanked for their participation and given the option to enter a raffle to win $\$ 100$. They were asked to provide an email address that can be used to contact them in the event that they win the raffle. This email address was not linked to their survey answers. A random number generator (http://www.random.org) was used to select an entry from the 214 participants who provided information for the raffle. The selected recipient was paid $\$ 100.00$.

\section{$\underline{\text { Measures }}$}

\section{Attachment}

Global and romantic attachment patterns were each measured using the Experiences in Close Relationships Scale - Short Form (ECR-SF; Wei, Russell, Mallinckrodt, \& Vogel, 2007). To assess global attachment, participants were asked to think about "the close relationships in your life, which may include friends, family, romantic partners, coworkers, and others," and the items referred to "those people." To assess romantic attachment, participants were asked to think about "your current romantic 
relationship," and the items referred to "your partner." The language of the items was otherwise identical. Participants rated 12 statements on a scale ranging from 1 (Definitely NOT like me) to 7 (Definitely like me). These statements comprised two subscales of six items each that reflect anxious and avoidant attachment patterns. The full ECR-SF can be scored as a single measure of insecure attachment, which is how we purposed this instrument for this study ${ }^{2}$. As scores on each subscale increase, insecure attachment is more strongly indicated; conversely, low scores are indicative of more secure attachment $^{3}$. This widely-used measure has yielded high estimates of internal reliability in its full form (e.g., Fraley, Brennan, \& Waller, 2000; Sibley \& Liu, 2003; Ravitz, Maunder, Hunter, Sthankiya, \& Lancee, 2010). In a reliability, validity, and factor structure analysis across six studies, the short form of the measure yielded factors and reliability consistent with the full form and robust construct validity using convergent and discriminant measures of related constructs. The ECR-SF can be found in Appendix 2. Cronbach's alphas for this study were .78 for the ECR-SF romantic scale and .78 for the ECR-SF global scale.

\section{Self-Esteem}

Self-esteem was measured using the Rosenberg Self-Esteem Scale (RSES; Rosenberg, 1979). Participants rated 10 statements about themselves (e.g., "I feel that I

\footnotetext{
${ }^{2}$ A reminder: Our outcome variables were carefully selected with the expectation (grounded in previous research) that their relationships to both anxious and avoidant attachment are in the same direction. This decision was made with the understanding that we will not be able to detect the potentially more nuanced relationships between the subtypes of attachment and our study outcomes, and we leave that task to future research.

${ }^{3}$ To emphasize: Higher scores represent more insecure attachment while lower scores represent more secure attachment.
} 
am a person of worth") on a Likert-type scale ranging from 1 (Strongly Agree) to 4 (Strongly Disagree). Increasing scores on this continuous measure are more indicative of low self-esteem. The RSES is one of the most frequently-used measures of self-esteem in existence. In a study of over 16,000 people across 53 nations, the RSES yielded good figures for factor structure, internal reliability, and both convergent and discriminant validity (Schmitt \& Allik, 2005). The RSES can be found in Appendix 3. The Cronbach's alpha for this study was .89.

\section{Psychological Wellbeing}

Psychological wellbeing was measured using the Schwartz Outcome Scale-10 (SOS-10, Blais et al., 1999). This widely-used measure is comprised of 10 statements about the self (e.g., "I feel hopeful about my future") that are rated on a Likert-type scale ranging from 0 (Never) to 7 (All the time). Higher scores on this single-factor, continuous measure are indicative of greater psychological health. Blais (2012) summarized the psychometrics of this measure, which consistently yields strong figures for factor structure, internal reliability, convergent and divergent validity, and clinical significance (e.g., Owen \& Imel, 2010). The SOS-10 can be found in Appendix 4. The Cronbach's alpha for this study was .90 .

\section{Dyadic Coping}

The Dyadic Coping Inventory (DCI; Bodenmann, 2008) is a 55-item measure assessing self, partner, and concurrent behaviors in times of stress; for the purpose of this study, we only used the subscales that measure self-referential behaviors (specifically, stress communication, supportive behaviors, negative behaviors, and delegated coping), which were used to create a total score for dyadic coping. This resulted in 15 statements 
about the self that were rated on a Likert-type scale from 0 (never) to 4 (very often). The DCI is a relatively recent instrument that was developed and normed on a German population and has subsequently been translated into several different languages in which it has been found to yield good reliability and validity figures across cultures (Ledermann, et al., 2010). A recent analysis of the English version of the DCI in over 700 participants in the United States yielded good figures for reliability estimates and concurrent/discriminant validity (Levesque, Lafontaine, Caron, \& Fitzpatrick, 2014). The DCI was used with permission from its developer, Dr. Bodemann, who provided scoring information. It can be found in Appendix 5. The Cronbach's alpha for this study was .79. Sexual Satisfaction

Sexual satisfaction was measured using the Global Measure of Sexual Satisfaction (GMSEX; Lawrence \& Byers, 1998). Participants were asked to rate their sexual relationship with their partner on five items each using a bipolar scale from 1 to 7 (e.g., Very Satisfying to Very Unsatisfying). In past studies, this measure has yielded good figures for internal consistency, test-retest reliability, and convergent validity (Byers \& MacNeil, 2006; Lawrence \& Byers, 1998; Péloquin et al., 2014). The GMSEX can be found in Appendix 6. The Cronbach's alpha for this study was .93.

\section{Relationship Commitment}

The Revised Commitment Inventory (RCI; Owen, Rhoades, Stanley, \& Markman, 2011) is comprised of items measuring both dedication and constraint commitment; for the purpose of this study we used only the dedication subscale. This scale consists of 8 statements about the participants' commitment to their romantic relationship (e.g., "My relationship with my partner is clearly part of my future life plans") rated on a Likert-type 
scale of 1 (Strongly agree) to 7 (Strongly Disagree). Based on the original Commitment Inventory (Stanley \& Markman, 1992), the revised version expanded the norming population by including unmarried couples (for example, couples who cohabitate but are not married) (Owen et al., 2011). Reliability and validity for the dedication subscale specifically has been supported by previous research (Kamp Dush, Rhoades, SandbergThoma, \& Schoppe-Sullian, 2014; Maddox Shaw, Rhoades, Allen, Stanley, \& Markman, 2013). The RCI can be found in Appendix 7. The Cronbach's alpha for this study was .88 . 


\section{CHAPTER III: RESULTS}

\section{$\underline{\text { Preliminary Analyses }}$}

Table 1 shows the means, standard deviations, ranges, and bivariate correlations for study variables global attachment, romantic attachment, self-esteem, psychological wellbeing, dyadic coping, sexual satisfaction, and relationship commitment. Nearly all pairwise correlations were statistically significant and of low to moderate strength (absolute values $.18 \leq r \leq .67$ ). For the most part, these relationships are unsurprising given that we are examining some of the fundamental components of individual and relational functioning (for example, the strongest correlation was between self-esteem and psychological wellbeing). Global and romantic attachment were correlated at a strength of $r=.49(p<.001)$, which is consistent with previous research (e.g., Treboux et al., 2004), and which supports the idea that global and romantic attachment are related but not redundant. Regarding our hypotheses, all outcome variables except sexual satisfaction were significantly related to global attachment $(-.50 \geq r \mathrm{~s} \geq-.17)$ and all outcome variables were significantly related to romantic attachment (-.47 $\geq r \mathrm{~s} \geq-.34)$, which is consistent with expectations.

Table 2 shows bivariate correlations between selected demographic variables (age, income, education, and relationship duration) and the study outcomes. Numerous small- to medium- sized effects between these demographics and the study variables were found. Notable among these were negative relationships between relationship duration and (a) dyadic coping $(r=-.15, p<.01)$ and (b) sexual satisfaction $(r=-.35, p<.001)$. 
Insecure global attachment had small-sized associations, but statistically significant, with all chosen demographic variables $(-.19<r<-.12)$, and for this reason age, income, education, and relationship duration were included in the primary analyses as controls.

To examine whether or not the magnitude of these relationships were significantly different from each other, a web-based statistical analysis tool (cocor; Diedenhofen \& Musch, 2015) was used to compare these correlations (see Table 3). We expected that the individual variables (self-esteem and wellbeing) would be more strongly related to global attachment than romantic attachment, and we expected that the relational variables (dyadic coping, sexual satisfaction, and relationship commitment) would be more strongly related to romantic attachment than global attachment. This was true in all cases except for wellbeing, which was more strongly related to romantic attachment, however, this difference ( $r=-.47$ for global vs. $r=-.42$ for romantic), was not significant. Regarding control variables, the only significant difference between insecure global and insecure romantic attachment was for age ( $r=-.19$ vs. $r=.03$, respectively). 
Table 1: Bivariate Correlations, Means, Standard Deviations, and Ranges

\begin{tabular}{|c|c|c|c|c|c|c|c|}
\hline & 1 & 2 & 3 & 4 & 5 & 6 & 7 \\
\hline $\begin{array}{l}\text { 1. Global } \\
\text { Insecure } \\
\text { Attachment }\end{array}$ & -- & & & & & & \\
\hline $\begin{array}{l}\text { 2. Romantic } \\
\text { Insecure } \\
\text { Attachment }\end{array}$ & $.49 * * *$ & -- & & & & & \\
\hline 3. Self-Esteem & $-.50 * * *$ & $-.36 * * *$ & -- & & & & \\
\hline 4. Wellbeing & $-.42 * * *$ & $-.47 * * *$ & $.67 * * *$ & -- & & & \\
\hline $\begin{array}{l}\text { 5. Dyadic } \\
\text { Coping }\end{array}$ & $-.31 * * *$ & $-.45 * * *$ & $.24 * * *$ & $.43 * * *$ & -- & & \\
\hline $\begin{array}{l}\text { 6. Sexual } \\
\text { Satisfaction }\end{array}$ & $-.10 n s$ & $-.34 * * *$ & $.18^{* *}$ & $.33 * * *$ & $.36^{* * *}$ & -- & \\
\hline $\begin{array}{l}\text { 7. Relationship } \\
\text { Commitment }\end{array}$ & $-.17 * *$ & $-.36 * * *$ & $.09 n s$ & $.24 * * *$ & $.36^{* * *}$ & $.29 * * *$ & -- \\
\hline Mean (SD) & $39.55(11.47)$ & $32.00(10.95)$ & $31.68(5.03)$ & $59.84(10.67)$ & $47.80(5.04)$ & $26.45(5.89)$ & $46.64(8.38)$ \\
\hline $\begin{array}{l}\text { Range } \\
\text { (min-max) }\end{array}$ & $63(15-78)$ & $54(12-66)$ & $23(17-40)$ & $61(19-80)$ & $27(33-60)$ & $26(9-35)$ & $38(18-56)$ \\
\hline
\end{tabular}

$* * p<.01, * * * p<.001, n s=$ not significant; "Range" reflects minimum and maximum scores obtained. 
Table 2: Bivariate Correlations for Demographic Variables and Outcomes

\begin{tabular}{|c|c|c|c|c|}
\hline & Age & Income & Education & $\begin{array}{c}\text { Relationship } \\
\text { Duration }\end{array}$ \\
\hline $\begin{array}{l}\text { Global } \\
\text { Insecure } \\
\text { Attachment }\end{array}$ & $-.19 * *$ & $-.12^{*}$ & $-.19 * *$ & $-.18 * *$ \\
\hline $\begin{array}{l}\text { Romantic } \\
\text { Insecure } \\
\text { Attachment }\end{array}$ & .03 & -.03 & $-.12 *$ & -.10 \\
\hline Self-Esteem & $.12 *$ & $.17 * *$ & $.18^{* *}$ & .04 \\
\hline Wellbeing & -.05 & .02 & $.12 *$ & -.06 \\
\hline Dyadic Coping & -.10 & -.11 & -.07 & $-.15 * *$ \\
\hline $\begin{array}{l}\text { Sexual } \\
\quad \text { Satisfaction }\end{array}$ & $-.15^{* *}$ & $-.13^{*}$ & .05 & $-.35 * * *$ \\
\hline $\begin{array}{l}\text { Relationship } \\
\text { Commitment }\end{array}$ & .04 & .07 & .05 & $.19 * *$ \\
\hline
\end{tabular}

$* p<.05 * * p<.01, * * * p<.001$. 
Table 3: Tests of Difference ${ }^{\ddagger}$ Between Correlates of Global and Romantic Attachment

\begin{tabular}{|c|c|c|c|c|c|c|c|c|c|}
\hline & & & & Relationship & Self- & & Sexual & Dyadic & Relationship \\
\hline & Age & Income & Education & Duration & Esteem & Wellbeing & Satisfaction & Coping & Commitment \\
\hline \multicolumn{10}{|l|}{ Global } \\
\hline $\begin{array}{l}\text { Insecure } \\
\text { Attachment }\end{array}$ & $-.19 * *$ & $-.12 *$ & $-.19 * *$ & $-.18 * *$ & $-.50 * * *$ & $-.42 * * *$ & $-.31 * * *$ & -.10 & $-.17^{* *}$ \\
\hline $\begin{array}{l}\text { Romantic } \\
\text { Insecure } \\
\text { Attachment }\end{array}$ & .03 & -.03 & $-.12 *$ & -.10 & $-.36 * * *$ & $-.47 * * *$ & $-.45 * * *$ & $-.34 * * *$ & $-.36 * * *$ \\
\hline $\begin{array}{l}\text { Are the } \\
\text { correlations } \\
\text { significantly } \\
\text { different at } \\
p<.05 ?\end{array}$ & Yes & No & No & No & Yes & No & Yes & Yes & Yes \\
\hline
\end{tabular}

${ }^{\dagger}$ The web-based statistical program cocor (Diedenhofen \& Musch, 2015) was used to compare these correlations (two-tailed test of dependent, overlapping data using $\alpha=.05$; confidence intervals $=95 \%$ ). The following tests were included in each analysis:

Pearson and Filon's (1898) z; Hotelling's (1940) t; Williams' (1959) t; Ilkin's (1967) z; Dunn and Clark's (1969) z; Hendrickson, Stanley, and Hills' (1970) modification of Williams' (1959) t; Steiger's (1980) modification of Dunn and Clark's (1969) z; Meng, Rosenthal, and Rubin's (1992) z; Hittner, May, and Silver's (2003) modification of Dunn and Clark's (1969) z; and Zou's (2007) confidence interval. For each case where cocor was used to compare correlations, these tests all produced equivalent results. Detailed statistics for each comparison are available upon request. 


\section{Primary Analyses}

For each of the following analyses, a linear regression was conducted using each study variable as the dependent variable, independent variables global attachment, romantic attachment, and global x romantic attachment (which were centered), and control variables age, income, education, and relationship duration. Assumptions of linear regression (independence, normality, homogeneity of variance, linearity, and collinearity) were checked and found to be satisfactory for each analysis. The results for the models can also be found in Table 4 .

\section{Hypothesis 1: Self Esteem}

It was anticipated that there would be a main effect of global attachment style for self-esteem in the form of a negative relationship between self-esteem and insecure global attachment. The model was found to be significant, $F(7,287)=18.5, p<.001$, adjusted $\mathrm{R}^{2}=.29$, indicating that $29 \%$ of the variance in self-esteem was explained by the model. Two control variables were significant: income $(B=.46, S E=.21, \beta=.13, p<$ $.05)$ and relationship duration $(B=-.38, S E=.18, p<.05)$. Those who reported greater income also reported higher self-esteem. Those who reported being a relationship longer reported lower self-esteem. Both insecure global attachment $(B=-.18,95 \%$ CI [-.23, $.13], S E=.02, \beta=-.42 p<.001)$ and insecure romantic attachment $(B=-.08,95 \%$ CI [$.14,-.03], S E=.02, \beta=-.19, p<.01)$ were found to be significant predictors within this model. Those who reported more insecure global and romantic attachment also reported lower self-esteem. The difference in magnitude of the standardized regression coefficients (moderate for insecure global attachment and weak for insecure romantic attachment) suggests that insecure global attachment may be a comparatively stronger 
predictor of self-esteem. This was also suggested by the lack of overlap of the 95\% confidence interval for the unstandardized regression coefficients. These results support Hypothesis 1.

\section{Hypothesis 2: Psychological Wellbeing}

It was anticipated that there would be a main effect of global attachment style for psychological wellbeing in the form of a negative relationship between psychological wellbeing and insecure global attachment. The model was found to be significant, $F(7$, $287)=18.18, p<.001$ adjusted $\mathrm{R}^{2}=.29$, indicating that $29 \%$ of the variance in psychological wellbeing was explained by the model. One control variable was significant: Relationship duration $(B=-1.01, S E=.38, \beta=-.15, p<.01)$. Those who reported longer relationship duration reported lower psychological wellbeing. Both insecure global attachment $(B=-.27,95 \%$ CI $[-.37,-.16], S E=.05, \beta=-.29, p<.001)$ and insecure romantic attachment $(B=-.34,95 \% \mathrm{CI}[-.45,-.23] S E=.06, \beta=-.36, p<$ .001) were found to be significant predictors within this model. The magnitude of the standardized regression coefficients was moderate for both insecure global attachment and insecure romantic attachment, and there was substantial overlap in the $95 \%$ confidence intervals for the unstandardized regression coefficients. Those who reported higher insecure global and romantic attachment reported lower psychological wellbeing. These results support Hypothesis 2.

\section{Hypothesis 3: Dyadic Coping}

It was anticipated that there would be a main effect of romantic attachment style for dyadic coping in the form of a negative relationship between dyadic coping and insecure romantic attachment. The model was found to be significant, $F(7,287)=17.03$, 
$p<.001$, adjusted $\mathrm{R}^{2}=.29$, indicating that $29 \%$ of the variance in dyadic coping was explained by the model. Two control variables were significant: education $(B=-.47, S E$ $=.2, \beta=-.12, p<.05)$ and relationship duration $(B=-.63, S E=.18, \beta=-.19, p<.01)$. As education and relationship duration increased, dyadic coping decreased. Both global attachment $(B=-.09,95 \%$ CI $[-.14,-.03], S E=.03, \beta=-.19, p<.01)$ and romantic attachment $(B=-.18,95 \%$ CI $[-.23,-.12], S E=.03, \beta=-.39, p<.001)$ were found to be significant predictors within this model. Participants who reported higher insecure global and romantic attachment reported worse dyadic coping. The difference in magnitude between the standardized regression coefficients (weak for insecure global attachment and moderate for insecure romantic attachment) suggests that insecure romantic attachment may be a comparatively stronger predictor of dyadic coping, however, there was overlap of the $95 \%$ confidence interval for the unstandardized regression coefficients. These results support Hypothesis 3.

Hypothesis 4: Sexual Satisfaction

It was anticipated that there would be a main effect of romantic attachment style for sexual satisfaction in the form of a negative relationship between sexual satisfaction and insecure romantic attachment. The model was found to be significant, $F(7,287)=$ $.28, p<.001$, adjusted $\mathrm{R}^{2}=.26$, indicating that $26 \%$ of the variance in sexual satisfaction was explained by the model. One control variable was significant: Relationship duration $(B=-1.46, S E=.22, \beta=-.39, p<.001)$. Participants who reported longer relationship duration reported lower sexual satisfaction. Romantic attachment $(B=-.22,95 \%$ CI [-.28, -.16], $S E=.03, \beta=-.41, p<.001)$ was found to be a significant predictor within this model. Global attachment, was not found to be a significant predictor, suggesting that 
insecure romantic attachment may be a stronger predictor of sexual satisfaction than insecure global attachment. This was also supported by the lack of overlap between the 95\% confidence intervals for the unstandardized regression coefficients. These results support Hypothesis 4.

\section{Hypothesis 5: Relationship Commitment}

It was anticipated that there would be an interaction of global and romantic attachment styles for relationship commitment as follows: Insecure global attachment will moderate the relationship between romantic attachment and these outcomes, and global attachment is less insecure/more secure, the relationship between romantic attachment and relationship commitment will grow stronger. The model was found to be significant, $F(7,287)=8.33, p<.001$, adjusted $\mathrm{R}^{2}=.15$, indicating that $15 \%$ of the variance in relationship commitment was explained by the model. One control variable was significant: Relationship duration $(B=.82, S E=.32, \beta=.16, p<.05)$. Participants who reported longer relationship duration reported higher relationship commitment. Insecure romantic attachment $(B=-.29,95 \% \mathrm{CI}[-.38,-.19] S E=.05, \beta=-.38, p<.001)$ was found to be a significant predictor within this model. Those who reported higher insecure romantic attachment reported lower relationship commitment, while global attachment was not a significant predictor, suggesting that insecure romantic attachment may be a stronger predictor of relationship commitment than insecure global attachment. This was also supported by the lack of overlap in the $95 \%$ confidence intervals for the unstandardized coefficients. Global x romantic attachment were not found to be significant predictors related to relationship commitment $(\mathrm{p}>.05)$. Hypothesis 5 was not supported by these results. 
Hypothesis 6: Additional Interactions

It was also anticipated that there would be an interaction of global and romantic attachment styles for self-esteem, psychological wellbeing, dyadic coping, and sexual satisfaction. However, the interaction term alone was not found to be a significant predictor in any of the analyses. 
Table 4: Multiple Regression

\begin{tabular}{|c|c|c|c|c|c|c|}
\hline & & $\begin{array}{c}\text { Self- } \\
\text { Esteem }\end{array}$ & Wellbeing & $\begin{array}{l}\text { Dyadic } \\
\text { Coping }\end{array}$ & $\begin{array}{c}\text { Sexual } \\
\text { Satisfaction }\end{array}$ & $\begin{array}{l}\text { Relationship } \\
\text { Commitment }\end{array}$ \\
\hline \multirow{3}{*}{ Age } & $B$ & $.003 n s$ & $-.05 n s$ & $-.02 n s$ & $-.01 n s$ & $.004 n s$ \\
\hline & $S E$ & .03 & .07 & .03 & .04 & .06 \\
\hline & $\beta$ & .005 & -.04 & -.04 & -.01 & .004 \\
\hline \multirow{3}{*}{ Income } & $B$ & $.46^{*}$ & $.26 n s$ & $-.08 n s$ & $.002 n s$ & $.09 n s$ \\
\hline & $S E$ & .21 & .44 & .21 & .25 & .38 \\
\hline & $\beta$ & .13 & .04 & -.02 & .000 & .02 \\
\hline \multirow{3}{*}{ Education } & $B$ & $.3 n s$ & $.34 n s$ & $-.47 *$ & $-.24 n s$ & $-.49 n s$ \\
\hline & $S E$ & .19 & .4 & .2 & .23 & .35 \\
\hline & $\beta$ & .08 & .04 & -.12 & .05 & -.08 \\
\hline \multirow{3}{*}{$\begin{array}{l}\text { Relation- } \\
\text { ship } \\
\text { Duration }\end{array}$} & $B$ & $-.38^{*}$ & $-1.01 * *$ & $-.63 * *$ & $-1.46 * * *$ & $.82 *$ \\
\hline & $S E$ & .18 & .38 & .18 & .22 & .32 \\
\hline & $\beta$ & -.18 & -.15 & -.19 & -.39 & .16 \\
\hline \multirow{4}{*}{$\begin{array}{l}\text { Insecure } \\
\text { Global } \\
\text { Attachment }\end{array}$} & $B$ & $-.18 * * *$ & $-.27 * * *$ & $-.09 * *$ & $.02 n s$ & $.01 n s$ \\
\hline & $95 \% C I$ & $-.23,-.13$ & $-.37,-.16$ & $-.14,-.03$ & $-.04, .08$ & $-.08, .10$ \\
\hline & $S E$ & .03 & .05 & .03 & .03 & .05 \\
\hline & $\beta$ & -.42 & -.29 & -.19 & .03 & .02 \\
\hline \multirow{4}{*}{$\begin{array}{l}\text { Insecure } \\
\text { Romantic } \\
\text { Attachment }\end{array}$} & $B$ & $-.08 * *$ & $-.34 * * *$ & $-.18 * * *$ & $-.22 * * *$ & $-.29 * * *$ \\
\hline & $95 \% C I$ & $-.14,-.03$ & $-.45,-.23$ & $-.23,-.12$ & $-.28,-.16$ & $-.38,-.19$ \\
\hline & $S E$ & .03 & .06 & .03 & .03 & .05 \\
\hline & $\beta$ & -.19 & -.36 & -.39 & -.41 & -.38 \\
\hline \multirow{3}{*}{$\begin{array}{l}\text { Insecure } \\
\text { Global x } \\
\text { Romantic } \\
\text { Attachment }\end{array}$} & $B$ & $.003 n s$ & $.004 n s$ & $-.002 n s$ & $.003 n s$ & $.02 n s$ \\
\hline & $S E$ & .002 & .004 & .002 & .002 & .003 \\
\hline & $\beta$ & .09 & .05 & -.06 & .06 & .09 \\
\hline
\end{tabular}

$* p<.05, * * p<.01, * * * p<.001, n s=$ not significant; items in italics represent controls 


\section{CHAPTER IV: DISCUSSION}

Attachment is a well-known psychological construct that has been researched extensively, however, a consistent understanding of its structure and function remains elusive. Our study sought to further explore the theory that global and romantic attachment patterns are distinct mechanisms that impact individual and relational variables differentially. We also examined the possibility that global and romantic patterns interact in a manner that reflects the progression of attachment patterns as a developmental characteristic sensitive to change.

Most noteworthy among our results is the theme of differentiation between global and romantic attachment patterns in their relationship to the study outcomes. These two constructs were related to the degree expected based on previous research, but despite this relationship they were found to differ in the magnitude of their relationship to several outcomes. Also noteworthy was the absence of interaction effects despite adequate power to detect them, suggesting that the potential relationship between global and romantic attachment may not match the model hypothesized for this study.

We first hypothesized that the individual variables self-esteem and psychological wellbeing would be related to global attachment. As anticipated, self-esteem was negatively related to insecure global attachment, a relationship that was higher in magnitude as compared to insecure romantic attachment. This is consistent with previous research (e.g., Foster, Kernis, \& Goldman, 2007). Self-esteem is by definition a highly self-referential trait, as it reflects a cognitive/emotional assessment of the self based on a 
constellation of factors (e.g., perception of one's success, cultural identity and status), which may be related more strongly to a global sense of self than one's identity in the context of a romantic relationship. This could be part of having a stronger attachment foundation from previous relationships (e.g., parents, friends, previous relationships) that constitutes a healthy sense of self regardless of the romantic relationship attachment. Higher self-esteem may act as a buffer against hyperactivation/deactivation associated with anxious/avoidant behaviors. Self-esteem may also fluctuate in response to the outcomes of attachment interactions, with more insecure interactions leading to lowered self-esteem.

While global attachment was more strongly associated with self-esteem, insecure romantic attachment was also associated with lower self-esteem, albeit to a potentially lesser degree. Previous research has also detected the latter relationship (e.g., Schmitt \& Allik, 2005). Perception of the self as a romantic partner may be one component of selfesteem and may therefore be influenced by the relational dynamics of one's current relationship. Romantic relationships in particular may carry a cultural/emotional weight as being central to our lives and/or identity, and are therefore relevant to self-esteem. For example, feeling cared for by a partner in a moment of emotional vulnerability may contribute to an increased sense of self-worth. Overall, our findings related to self-esteem support the idea that self-esteem may play a role in the emotional regulation involved in the attachment process and vice versa.

As anticipated, psychological wellbeing was negatively related to insecure global attachment. In addition to what was hypothesized, it was also negatively related to romantic attachment. This is consistent with previous research drawing a relationship 
between secure attachment and higher psychological wellbeing (e.g. Cozzarelli et al., 2000) and research indicating that insecure attachment is associated with higher incidence of psychological disorders (Mikelson, Kessler, \& Shaver, 1997). Psychological wellbeing and global attachment reflect similar ways of being in the world, as they are each global states potentially reflected in sound relational dynamics as well as personal and meaningful introjects in one's lived experience. Additionally, being more healthy relationally and physically is likely to influence the security in the bonds with others globally and more romantically. As it relates to romantic relationships, perhaps these relationships are so central to our lives that our relational functioning significantly impacts our state of being (and vice versa). The correlational nature of our analyses does not allow us to make inferences regarding these relationships, but it does seem likely that reciprocal influences are evident. It is notable that the way we measured wellbeing includes some relational references (e.g., "I have confidence in my ability to sustain important relationships" and "I am able to handle conflicts with others" in the SOS), as this may have inflated the relationship between wellbeing and romantic attachment.

We also hypothesized that the relational variables dyadic coping and sexual satisfaction would be related to romantic attachment, and more so than global attachment. As anticipated, dyadic coping was negatively related to insecure romantic attachment, and this was higher in magnitude compared to global attachment. This is consistent with previous research (e.g., Fuenfhausen \& Cashwell, 2013). Dyadic coping reflects the nature of couple interactions; for this study, we captured information about how couples cope and communicate when under stress (such as asking for help), and other supportive and negative behaviors (e.g., expressing empathy; withdrawal). Factors that are central to 
romantic attachment, such as the balance of dependence vs. autonomy in a relationship, are reflected in these behaviors. Not only does dyadic coping involve regulation strategies targeting the self, but also attempts to regulate one's partner (Overall, \& Lemay, 2015), which reflects a process unique to the romantic relationship and therefore more strongly related to romantic attachment patterns.

Dyadic coping was also negatively related to insecure global attachment, although this relationship was weaker in magnitude compared to romantic attachment. It may be that dyadic coping is guided in part by more global aspects of attachment - for example, the degree to which someone believes another person should cope with their problems on their own (one component of dyadic coping) may be related more to a global valuing of personal autonomy than it is to a relationship-specific belief. For both romantic and global attachment, we cannot use our correlational data to draw causal conclusions about the mechanism of these relationships. It may be that a person who enters into a relationship with higher insecure attachment is less likely to engage in healthy dyadic coping; it may be that lower rates of healthy dyadic behaviors contribute to fluctuations in attachment. It seems most likely that some combination of the two is the most accurate reflection of these dynamics.

As anticipated, sexual satisfaction was negatively related to insecure romantic attachment. This is consistent with previous research (e.g., Birnbaum, 2010; Brassard et al., 2012) linking insecure attachment with lower emotional and physiological sexual fulfillment. Attachment dynamics as described by Mikulincer, Shaver, \& Pereg (2003; Fig. 1) may occur in the context of any given sexual interaction as follows: (a) sexual desire or situational factors (e.g., nudity) cultivate feelings of vulnerability which activate 
proximity/reassurance-seeking behaviors (e.g., bid for affectionate touch); (b) the sexual partner does or does not respond to that bid, leading to (c) increased comfort/confidence in the moment (and more fulfilling sex) or (d) anxious/avoidant behaviors (and less fulfilling sex). This pattern may repeat as a series of micro-moments throughout a single sexual encounter. Notably, global attachment was not significantly related to sexual satisfaction, providing support for the idea that relationship-specific attachment mechanisms are distinct. Sexual interaction is one defining factor that differentiates romantic relationships from all others; it follows easily that relational dynamics related to sex are likely to be guided by internal processes specific to this relationship type.

We hypothesized an interaction between global and romantic attachment in which the relationship between romantic attachment and relationship commitment would be stronger as global attachment is more secure. There was no support for this interaction effect. However, relationship commitment was negatively related to insecure romantic attachment and, to a lesser extent, insecure global attachment. This suggests that attachment interactions contributing to relationship commitment may be guided more by romantic attachment than global attachment. This may in part be related to our decision to measure relationship commitment in terms of dedication, which reflects value- and emotion-based judgments of one's relationship (one item states, "My relationship with my partner is more important to me than almost anything in my life"). Dedication commitment is arguably more partner-focused than constraint commitment (e.g., financial and housing entanglement). Previous research supports the theory that relationship commitment functions as a buffer against relational anxiety and avoidance (Stanley, Rhoades, \& Whitton, 2010) 
Finally, we investigated the possibility for interaction effects in each of the other study variables. We hypothesized that that the relationship between insecure romantic attachment and the individual study variables self-ssteem and psychological wellbeing would be stronger as global attachment became more secure (amplifying the insecurity of the relationship in contrast to global expectations) and that the relationship between insecure romantic global attachment and the relational variables dyadic coping and sexual satisfaction would be weaker as romantic attachment became more secure (acting as a reparative function). None of these relationships were found to be significant, therefore there was no support for this hypothesis.

A number of significant relationships were also observed among our control variables. The most noteworthy of these was relationship duration, which was positively related to relationship commitment, an unsurprising result. Relationship duration was negatively related to self-esteem, wellbeing, dyadic coping, and sexual satisfaction. While these relationships may seem counterintuitive, it possible that developmental influences could be at play. For example, about $70 \%$ of our participants reported relationships under 10 years in duration and $75 \%$ were between the ages of 25 and 40 . Perhaps many of our respondents are experiencing their peak relationship duration in the midst of the most demanding years of child rearing, during which personal and relational factors tend to suffer (see Nelson, Kushlev, and Lyubomirsky, 2014, for a review). Because we did not collect information about parenthood, this possibility cannot be tested. Regarding other relationships between control variables, income was positively related to self-esteem (see Twenge \& Campbell, 2002, for a meta-analysis supporting this finding) and education was negatively related to dyadic coping. The latter finding was not 
supported in a 2015 meta-analysis of dyadic coping and correlates (Falconier, Jackson, Hilpert, \& Bodenmann, 2015). Unfortunately, the income data we collected were not collected with enough detail to adequately examine this finding. While the median income in the U.S. is just under \$29k annually (U.S. Census Bureau, 2015), about $75 \%$ of our participants reported a personal income of over $\$ 50 \mathrm{k}$. This suggests that our sample is a poor representation of the population where income is concerned and may therefore be less likely to conform to figures obtained from previous research.

\section{$\underline{\text { Limitations }}$}

Numerous limitations exist that should be taken into account when interpreting these results. Our study sample was overwhelmingly white, formally educated, female, and cisgender, with only slightly more variation in income (skewed high) and sexual identity (skewed straight). These trends toward homogeneity compromise external validity as our results are less generalizable to the general population. We measured insecure attachment without separating anxious and avoidant components ${ }^{4}$, and while we took this into careful consideration in variable selection and study design, the lack of separation between these categories of attachment represents a compromise of internal validity, as nuances related to types of insecure attachment were not detectable. We also collected our data in the form of a single instance brief questionnaire, without pursuit of additional clarification or qualitative data to help explain the results. Collecting data at a single time point enables us to detect correlational relationships only, so conclusive

\footnotetext{
${ }^{4}$ Confidential to the committee: I ran these analyses and the results were not notably different than what is reported in this study.
} 
causal inferences are not possible. Our use of a single test instrument for each of the variables was a compromise of construct validity, as it limits the amount of information captured and does not provide the option to strengthen internal validity using convergence of measures. Construct validity may also be impacted by the fact that each participant response set represents the self-report of one person in a two-person relationship, and is therefore an incomplete reflection of the relational dynamic. Finally, there were some minor points that this researcher would do differently the next time - for example, measuring relationship duration by the exact number of years and months, instead of consolidating it into a set of categories. Given that relationship duration became a meaningful control variable, having the additional detail would have enabled us to better understand our results.

\section{$\underline{\text { Implications and Future Directions }}$}

The broad purpose of this study was to further an extant line of inquiry suggesting that attachment patterns are impacted by relationships beyond those with early caregivers and may in fact vary in the context of a lifetime. Although our data were collected at a single time point and therefore do not illustrate change over time, these study results are consistent with a model of attachment in which these patterns of emotional regulation and relational interaction vary based on relationship type and are differentially related to fundamental individual and relational outcomes. It is well-established that attachment patterns are grounded in childhood experience; however, the potential for these patterns to be impacted by our experiences is critical to the question of whether or not healing is possible. Does inadequate parenting doom us to a lifetime of romantic relationships defined by anxiety or avoidance? Is it possible to cultivate more secure attachment by 
engaging in relationships defined by healthy behaviors? Can one partner's secure relational behaviors impact not only their relationship dynamics, but their partner's future attachment patterns? Our study does not answer these questions, but it does add weight to the idea that romantic relationships impact or are impacted by attachment patterns beyond the traditional conceptualization of the fixed and generalized "attachment style."

We observed a correlation between global and romantic attachment that was consistent with previous research (e.g., Treboux et al., 2004) and represents a moderate relationship that leaves room for differential functioning. Unexpectedly, romantic attachment was significantly related to all study outcomes. These results highlight the importance of romantic attachment not only where relational functioning is concerned, but also in the realm of global functioning. Viewing attachment as a fixed and unitary construct fails to account for the influence of relationship-specific dynamics, and we therefore have a responsibility as researchers to continue to pursue a more complex understanding of attachment using a developmental framework. In the context of romantic relationships, this means being open to the possibility that change can occur with deliberate and intentional intervention.

In the future, we hope to see research that combines our study's investigation of global vs. specific attachment patterns with the ability to measure change over time. Improvements made to study design (such as the separation of attachment subtypes and other issues identified as limitations in our study) are warranted in order to improve our ability to draw meaningful inferences. For example, it may be worthwhile to investigate the possibility that healthy dyadic functioning and/or relational satisfaction mediates the relationship between romantic attachment and personal outcomes such as wellbeing, and 
that these factors can be manipulated to improve relational and personal functioning. To accomplish this, we must include attachment patterns as active elements of experimental studies designed not only to observe correlational relationships but that actually target the emotional and behavioral components of insecure attachment. Developing a wellexplicated model of global and specific attachment that holds up across the broadly variable nature of the human experience is merely one important step toward using that understanding to develop effective methods of attachment repair. 


\section{REFERENCES}

Agishtein, P. \& Brumbaugh, C. (2013). Cultural variation in adult attachment: The impact of ethnicity, collectivism, and country of origin. Journal of Social, Evolutionary, and Cultural Psychology, 7, 384-405.

Aiken, L. S., \& West, S. G. (1991). Multiple regression: Testing and interpreting interactions. Thousand Oaks, CA: Sage Publications, Inc.

Ainsworth, M. D. \& Bell, S. M. (1970). Attachment, exploration, and separation: Illustrated by the behavior of one-year-olds in a strange situation. Child Development, 41, 49-67.

Beaulieu-Pelletier, G., Philippe, F. L., Lecours, S., \& Couture, S. (2011). The role of attachment avoidance in extradyadic sex. Attachment \& Human Development, 13, 193-313.

Ben-Naim, S., Hirschenberger, G., Ein-Dor, T., \& Mikulincer, M. (2013). An experimental study of emotion regulation during relationship conflict interactions: The moderating role of attachment orientations. Emotion, 13, 506-519.

Birnbaum, G. E. (2007). Attachment orientations, sexual functioning, and relationship satisfaction in a community sample of women. Journal of Social and Personal Relationships, 24, 21-35.

Birnbaum, G. E. (2010). Bound to interact: The divergent goals and complex interplay of attachment and sex within romantic relationships. Journal of Social and Personal Relationships, 27, 245-252. 
Birnie, C., McClure, M. J., Lydon, J. E., \& Holmberg, D. (2009). Attachment avoidance and commitment aversion: A script for relationship failure. Personal Relationships, 16, 79-97.

Blais, M. A., Lenderking, W. R., Baer, L., deLorell, A., Peets, K., Leahy, L. \& Burns, C. (1999). Development and initial validation of a brief mental health outcome measure. Journal of Personality Assessment, 73, 359-373.

Blais, M. A. (2012). The Schwartz Outcome Scale - 10 (SOS) - 10. Integrating Science and Practice, 2, 40-42.

Bodenmann, G., Bradbury, T. N., Pihet, S. (2008). Relative contributions of treatmentrelated changes in communication skills and dyadic coping skills to the longitudinal course of marriage in the framework marital distress prevention. Journal of Divorce and Remarriage, 50, 1-21.

Bodenmann, G., Meuwly, N., \& Kayser, K. (2011). Two conceptualizations of dyadic coping and their potential for predicting relationship quality and individual wellbeing: A comparison. European Psychologist, 16, 255-266.

Bowlby, J. (1969). Attachment and loss: Vol 1. Attachment. New York: Basic Books. Bowlby, J (1982). Attachment and loss: Retrospect and prospect. American Journal of Orthopsychiatry, 52, 664-478.

Brassard, A., Péloquin, K., Dupuy, E., Wright, J., \& Shaver, P. R. (2012). Romantic attachment insecurity predicts sexual dissatisfaction in couples seeking marital therapy. Journal of Sex \& Marital Therapy, 38, 245-262.

Butzer, B., \& Campbell, L. (2008). Adult attachment, sexual satisfaction, and relationship satisfaction: A study of married couples. Personal Relationships, 15, 141-154. 
Bylsma, W. H., Cozzarelli, C., \& Sumer, N. (1997). Relation between adult attachment styles and global self-esteem. Basic and Applied Social Psychology, 19, 1-16.

Caron, A., Lafontaine, M-F., Bureau, J-F., Levesque, C., \& Johnson, S. (2012).

Comparisons of close relationships: An evaluation of relationship quality and patterns of attachment to parents, friends, and romantic partners in young adults. Canadian Journal of Behavioral Science, 44, 245-256.

Collins, N. L. \& Feeney, B. C. (2000). A safe haven: an attachment theory perspective on support seeking and caregiving in intimate relationships. Interpersonal Relations and Group Processes, 78, 1053-1073.

Collins, N. L. \& Read, S. J. (1990). Adult attachment, working models, and relationship quality in dating couples. Journal of Personality and Social Psychology, 58, 644663.

Consedine, N. S. \& Fiori, K. L. (2009). Gender moderates the associations between attachment and discrete emotions in late middle age and later life. Aging \& Mental Health, 13, 847-862.

Cozzarelli, C., Hoekstra, S. J., and Bylsma, W. H. (2000). General versus specific mental models of attachment: Are they associated with different outcomes? Personality and Social Psychology Bulletin, 26, 605-618.

Creasey, G. \& Jarvis, P. (2008). Attachment theory and research: A special focus on relationship initiation. In S. Sprecher, A. Wenzel, J. Harvey (Eds.), Handbook of relationship initiation (pp. 75-94). New York: Psychology Press.

Crowell, J. A., Treboux, D., Gao, Y., Fyffe, C., Pan, H., \& Waters, E. (2000). Assessing secure base behavior in adulthood: Development of a measure, links to adult 
attachment representation, and relations to couples' communication and reports of relationships. Developmental Psychology, 38, 679-693.

Diedenhofen, B. \& Musch, J. (2015). cocor: A Comprehensive Solution for the Statistical Comparison of Correlations. PLoS ONE, 10(4): e0121945. doi:10.1371/journal.pone.0121945

Falconier, M. K., Jackson, J. B., Hilpert, P., \& Bodenmann, G. (2015). Dyadic coping and relationship satisfaction: A meta-analysis. Clinical Psychology Review, 42, $28-46$.

Feeney, J. A. \& Noller, P. (1990). Attachment style as a predictor of adult romantic relationships. Journal of Personality and Social Psychology, 58, 281-291.

Forsythe, L. P., Romano, J. M., Jensen, M. P. \& Thorn, B. E. (2012). Attachment style is associated with perceived spouse responses and pain-related outcomes. Rehabilitation Psychology, 57, 290-300.

Fraley, R. C., Waller, N. G., \& Brennan, K. A. (2000). An item response theory analysis of self-report measures of adult attachment. Journal of Personality and Social Psychology, 78, 350-365.

Fraley, R. C., Heffernan, M. E., Vicary, A. M., \& Brumbagh, C. C. (2011A). The experience in close relationships - relationship structures questionnaire: A method for assessing attachment orientations across relationships. Psychological Assessment, 3, 615-625.

Fraley, R. C., Vicary, A. M., Brumbaugh, C. C., \& Roisman, G. I. (2011B). Patterns of stability in adult attachment: An empirical test of two models of continuity and change. Journal of Personality and Social Psychology, 101, 974-992. 
Fuenfhausen, K. K., \& Cashwell, C. S. (2013). Attachment, stress, dyadic coping, and marital satisfaction of counseling graduate students. The Family Journal, 21, 364370.

Gallo, L.C., \& Smith, T. W. (2001). Attachment style in marriage: Adjustment and responses to interaction. Journal of Social and Personal Relations, 18, 263-289.

Gomez, R., \& McLaren, S. (2007). The inter-relations of mother and father attachment, self-esteem and aggression during late adolescence. Aggressive Behavior, 33, 160-169.

Gorrese, A., \& Ruggieri, R. (2013). Peer attachment and self esteem: A meta-analytic view. Personality and Individual Differences, 55, 559-568.

Grossman, K. E. (1999). Old and new working models of attachment: The organization of feelings and language. Attachment \& Human Development, 1, 253-269.

Hadden, B. W., Smith, C. V., Webster, G. D. (2014). Relationship duration moderates associations between attachment and relationship quality: Meta-analytic support for the temporal adult romantic attachment model. Personality and Social Psychology Review, 18, 42-58.

Haydon, K. C., Collins, W. A., Salvatore, J. E., Simpson, J. A., Roisman, G. I. (2012). Shared and distinctive origins and correlates of adult attachment representations: The developmental organization of romantic functioning. Child Development, 83, 1689-1702.

Hazan, C. \& Shave, P. (1987). Romantic love conceptualized as an attachment process. Journal of Personality and Social Psychology, 52, 511-524. 
Huang, C. (2010). Mean-level change in self-esteem from childhood through adulthood: Meta-analysis of longitudinal studies. Review of General Psychology, 14, 251260.

Kamp-Dush, C. M., Rhoades, G. K., Sandberg-Thoma, S. E., \& Schoppe-Sullivan, S. J. (2014). Commitment across the transition to parenthood among married and cohabiting couples. Couple and Family Psychology: Research and Practice, 3, 126-136.

Kafetsios, K. \& Sideridis, G. D. (2006). Attachment, social support and wellbeing in young and older adults. Journal of Health Psychology, 11, 863-876.

Kaitz, M., Bar-Haim, Y., Lehrer, M., \& Grossman, E. (2004). Adult attachment style and interpersonal distance. Attachment \& Human Development, 6, 285-304.

Karreman, A. \& Vingerhoets, J. J. M. (2012). Attachment and wellbeing: The mediating role of emotion regulation and resilience. Personality and Individual Differences, $53,821-826$.

Klohnen, E. C., Weller, J. A., Luo, S., \& Choe, M. (2005). Organization and predictive power of general and relationship-specific attachment models: One for all, and all for one? Personality and Social Psychology Bulletin, 31, 1665-1682.

La Guardia, J. G., Ryan, R. M., Couchman, C. E., Deci, E. L. (2000). Within-person variation in security of attachment: A self-determination theory perspective on attachment, need fulfillment, and wellbeing. Journal of Personality and Social Psychology, 79, 367-384. 
Lavy, S. \& Littman-Ovadia, H (2011). All you need is love? Strengths mediate the negative associations between attachment orientations and life satisfaction. Personality and Individual Differences, 50, 1050-1055.

Lawrance, K., Byers, E. S., \& Cohen, J. N. (1998). Interpersonal exchange model of sexual satisfaction questionnaire. In T. D. Fisher, C. M. Davis, W. L. Yarber, \& S. L. Davis (Eds.), Handbook of sexually-related measures ( $3^{\text {rd }}$ ed.). New York: Routledge.

Le, B., \& Agnew, C. R. (2003). Commitment and its theorized determinants: A metaanalysis of the investment model. Personal Relationships, 10, 37-57.

Ledermann, T., Bodenmann, G., Gagliardi, S., Charvoz, L., Verardi, S., Rossier, J., ... lafrate, R. (2010). Psychometrics of the dyadic coping inventory in three language groups. Swiss Journal of Psychology, 69, 201-212.

Levesque, C., Lafontaine, M-F., Caron, A., \& Fitzpatrick, J. (2014). Validation of the English version of the dyadic coping inventory. Measurement and Evaluation in Counseling and Development, 47, 215-225.

Maddox Shaw, A. M., Rhoades, G. K., Allen, E. S., Stanley, S. M., \& Markman, H. J. (2013). Predictors of extradyadic sexual involvement in unmarried opposite-sex relationships. Journal of Sex Research, 50, 598-610.

Mehta, N., Cowen, P. A., \& Cowan, C. P. (2009). Working models of attachment to parents and partners: Implications for emotional behavior between partners. Journal of Family Psychology, 23, 895-899.

Meuwly, N., Bodenmann, G., Germann, J., Bradbury, T. N., Ditzen, B., \& Heinrichs, M. (2012). Dyadic coping, insecure attachment, and cortisol stress recovery 
following experimentally induced stress. Journal of Family Psychology, 26, 937947.

Miga, E. M., Hare, A., Allen, J. P., \& Manning, N. (2010). The relation of insecure attachment states of mind and romantic attachment styles to adolescent aggression in romantic relationships. Attachment \& Human Development, 12, 463-481.

Mickelson, K. D., Kessler, R. C., \& Shaver, P. R. (1997). Adult attachment in a nationally representative sample. Journal of Personality and Social Psychology, 73, 1092-1106.

Mikulincer, M., Florian, V., Cowan, P. A., \& Cowan, C. P. (2002). Attachment security in couple relationships: A systematic model and its implications for family dynamics. Family Process, 41, 405-434.

Mikulincer, M., Shaver, P. R., \& Pereg, D. (2003). Attachment theory and affect regulation: The dynamics, development, and cognitive consequences of attachment-related strategies. Motivation and Emotion, 27, 77-102.

Nelson, S. K., Kushlev, K., \& Lyubomirsky, S. (2014). The pains and pleasures of parenting: When, why, and how is parenthood associated with more or less wellbeing? Psychological Bulletin, 140, 846-897.

Osborne, J. W. (2012). Best Practices in Data Cleaning: A Complete Guide to Everything You Need to Do Before and After Collecting Your Data. Thousand Oaks, CA: Sage Publications.

Otway, L. J., \& Carnelley, K. B. (2013). Exploring the associations between adult attachment security and self-actualization and self-transcendence. Self and Identity, 12, 217-230. 
Overall, N. C., Fletcher, G. J. O., Friesen, M. D. (2003). Mapping the intimate relationship mind: Comparisons between three models of attachment representations. Personality and Social Psychology Bulletin, 29, 1479-1493.

Overall, N. C., Girme, Y. U., Lemay, Jr., E. P., \& Hammond, M. D. (2014). Attachment anxiety and reactions to relationship threat: The benefits and costs of inducing guilt in romantic partners. Journal of Personality and Social Psychology, 106, 235-256.

Overall, N. C. \& Lemay, E. P. (2015). Attachment and dyadic regulation process. In J.A. Simpson \& W. S. Rholes (Eds.) Attachment theory and research: New directions and emerging themes (9-38). New York: The Guilford Press.

Owen, J., \& Imel, Z. (2010). Rating scales in psychotherapy practice. In Handbook of clinical rating scales and assessment in psychiatry and mental health (pp. 257270). New York: Humana Press.

Owen, J., Rhoades, G. K., Stanley, S. M., \& Markman, H. J. (2011). The revised commitment inventory: Psychometrics and use with unmarried couples. Journal of Family Issues, 32, 820-841.

Papp, L. M., \& Witt, N. L. (2010). Romantic partners' individual coping strategies and dyadic coping: Implications for relationship functioning. Journal of Family Psychology, 24, 551-559.

Paradiso, S., Naridze, R., \& Holm-Brown, E. (2011). Lifetime romantic attachment style and social adaptation in late-onset depression. International Journal of Geriatric Psychiatry, 27, 1008-1016. 
Péloquin, K., Brassard, A., Lafontaine, M-F., Shaver, P. R. (2014). Sexually examined through the lens of attachment theory: attachment, caregiving, and sexual satisfaction. Journal of Sex Research, 51, 561-576.

Pierce, T. \& Lydon, J. E. (2001). Global and specific relational models in the experience of social interactions. Journal of Personality and Social Psychology, 80, 613-631.

Pierrehumbert, B., Torrisi, R., Ansermet, F., Borghini, A., \& Halfon, O. (2012). Adult attachment representations predict cortisol and oxytocin responses to stress. Attachment \& Human Development, 14, 453-476.

Pinquart, M., Feußner, C., \& Ahnert, L. (2013). Meta-analytic evidence for stability in attachments from infancy to early adulthood. Attachment \& Human Development, 15, 189-218.

Ravitz, P., Maunder, R., Hunter, J., Sthankiya, B., \& Lancee, W. (2010). Adult attachment measures: A 25-year review. Journal of Psychosomatic Research, 69, 419-432.

Roisman, G. I., Collins, W. A., Sroufe, L. A. \& Egeland, B. (2005). Predictors of young adults' representations of and behavior in their current romantic relationship: Prospective tests of the prototype hypothesis. Attachment \& Human Development, 7, 105-121.

Rosenberg, M. (1979). Conceiving the Self. Malabar, Florida: Robert E. Krieger.

Rosenberg, M., Schooler, C., Schoenbach, C., \& Rosenberg, F. (1995). Global selfesteem and specific self-esteem: Different concepts, different outcomes. American Sociological Review, 60, 141-156. 
Ross, L. R. \& Spinner, B. (2001). General and specific attachment representations in adulthood: Is there a relationship? Journal of Social and Personal Relationships, $18,747-766$.

Sadikaj, G., Moskowitz, D. S., Zuroff, D. C. (2011). Attachment-related affective dynamics: Differential reactivity to others' interpersonal behavior. Journal of Personality and Social Psychology, 100, 905-917.

Schmitt, D. P., \& Allik, J. (2005). Simultaneous administration of the Rosenberg selfesteem scale in 53 nations: Exploring the universal and culture-specific features of global self-esteem. Journal of Personality and Social Psychology, 89, 623-642.

Shaver, P., \& Mikulincer, M. (2002). Attachment-related psychodynamics. Attachment \& Human Development, 4, 133-161.

Sibley, C. G., \& Liu, J. H. (2003). Short-term temporal stability and factor structure of the revised experiences in close relationships (ECR-R) measure of adult attachment. Personality and Individual Differences, 36, 969-975.

Sibley, C. G. \& Overall, N. C. (2007). The boundaries between attachment and personality: Associations across three levels of the attachment network. Journal of Research in Personality, 41, 960-967.

Slotter, E. B., \& Finkel, E. J. (2009). The strange case of sustained dedication to an unfulfilling relationship: Predicting commitment and breakup from attachment anxiety and need fulfillment within relationships. Personality and Social Psychology Bulletin, 35, 85-100.

Sochos, A. (2013). The defining constituents of adult attachment and their assessment. Journal of Adult Development, 20, 87-99. 
Spencer-Rodgers, J., Peng, K., Wang, L., \& Hou, Y. (2004). Dialectical self-esteem and east-west differences in psychological wellbeing. Personality and Social Psychology Bulletin, 30, 1416-1432.

Sroufe, L. A. (2005). Attachment and development: A prospective, longitudinal study from birth to adulthood. Attachment \& Human Development, 7, 349-367.

Stanley, S. M., \& Markman, H. J. (1992). Assessing commitment in personal relationships. Journal of Marriage and Family, 54, 595-608.

Stanley, S. M., Rhoades, G. K., \& Whitton, S. W. (2010). Commitment: Functions, formation, and the securing of romantic attachment. Journal of Family Theory and Review, 2, 243-257.

Stanley, S. M., Markman, H. J., \& Whitton, S. W. (2002). Communication, conflict, and commitment: Insights on the foundations of relationship success from national survey. Family Process, 41, 659-675.

Stanley, S. M., Rhoades, G. K., Whitton, S. W. (2010). Commitment: Functions, formation, and the securing of romantic attachment. Journal of Family Theory, 2, 243-257.

Starks, T. J., \& Parsons, J. T. (2014). Adult attachment among partnered gay men: Patterns and associations with sexual relationship quality. Archives of Sexual Behavior, 43, 107-117.

Tran, S., \& Simpson, J. A. (2009). Prorelationship maintenance behaviors: The joint roles of attachment and commitment. Journal of Personality and Social Psychology, 97, 685-698. 
Treboux, D., Crowell, J. A., \& Waters, E. (2004). When "new" meets “old”:

configurations of adult attachment representations and their implications for marital functioning. Developmental Psychology, 40, 295-314.

Twenge, J. M., \& Campbell, W. K. (2002). Self-esteem and socioeconomic status: A meta-analytic review. Personality and Social Psychology Review, 6, 59-71.

U.S. Census Bureau (2015). Selected characteristics of people 15 years old and over by total money income in 2014, work experience in 2014, race, Hispanic origin, and sex. Retrieved June 12, 2016 from https://www.census.gov/data/tables/timeseries/demo/income-poverty/cps-pinc/pinc-01.html.

Van IJzendoorn, M. H. \& Bakremans-Kranenburg, M. J. (1996). Attachment representations in mothers, fathers, adolescents, and clinical groups: A metaanalytic search for normative data. Journal of Counseling and Clinical Psychology, 64, 8-21.

Waters, E., Merrick, S., Treboux, D., Crowell, J., \& Albersheim, L. (2000). Attachment security in infancy and early adulthood: A twenty-year longitudinal study. Child Development, 71, 684-689.

Wei, M., Liao, K. Y-H., Ku, T-Y., \& Shaffer, P. A. (2011). Attachment, self-compassion, empathy, and subjective wellbeing among college students and community adults. Journal of Personality, 79, 191-221.

Wei, M., Russell, D. W., Mallinckrodt, B., \& Vogel, D. L. (2007). The experiences in close relationship scale (ECR)-short form: Reliability, validity, and factor structure. Journal of Personality Assessment, 88, 187-204. 
Wei, M., Shaffer, P. A., Young, S. K., \& Zakalik, R. A. (2005). Adult attachment, shame, depression, and loneliness: The mediation role of basic psychological needs satisfaction. Journal of Counseling Psychology, 52, 591-601.

Wood, N. D., Werner-Wilson, R. J., Parker, T. S., Perry, M. S. (2002). Exploring the impact of attachment anxiety and avoidance on the perception of couple conflict. Contemporary Family Therapy, 34, 416-428.

Zhang, F., \& Labouvie-Vief, G. (2004). Stability and fluctuation in adult attachment style over a 6-year period. Attachment \& Human Development, 6, 419-437. 


\section{TABLES}

Table 1: Bivariate Correlations, Means, Standard Deviations, and Ranges

\begin{tabular}{|c|c|c|c|c|c|c|c|}
\hline & 1 & 2 & 3 & 4 & 5 & 6 & 7 \\
\hline $\begin{array}{l}\text { 1. Global } \\
\text { Insecure } \\
\text { Attachment }\end{array}$ & -- & & & & & & \\
\hline $\begin{array}{l}\text { 2. Romantic } \\
\text { Insecure } \\
\text { Attachment }\end{array}$ & $.49 * * *$ & -- & & & & & \\
\hline 3. Self-Esteem & $-.50 * * *$ & $-.36^{* * *}$ & -- & & & & \\
\hline 4. Wellbeing & $-.42 * * *$ & $-.47 * * *$ & $.67 * * *$ & -- & & & \\
\hline $\begin{array}{l}\text { 5. Dyadic } \\
\text { Coping }\end{array}$ & $-.31 * * *$ & $-.45^{* * *}$ & $.24 * * *$ & $.43 * * *$ & -- & & \\
\hline $\begin{array}{l}\text { 6. Sexual } \\
\text { Satisfaction }\end{array}$ & $-.10 n s$ & $-.34 * * *$ & $.18^{* *}$ & $.33 * * *$ & $.36^{* * *}$ & -- & \\
\hline $\begin{array}{l}\text { 7. Relationship } \\
\text { Commitment }\end{array}$ & $-.17 * *$ & $-.36 * * *$ & $.09 n s$ & $.24 * * *$ & $.36^{* * *}$ & $.29 * * *$ & -- \\
\hline Mean (SD) & $39.55(11.47)$ & $32.00(10.95)$ & $31.68(5.03)$ & $59.84(10.67)$ & $47.80(5.04)$ & $26.45(5.89)$ & $46.64(8.38)$ \\
\hline $\begin{array}{l}\text { Range } \\
(\min -\max )\end{array}$ & $63(15-78)$ & $54(12-66)$ & $23(17-40)$ & $61(19-80)$ & $27(33-60)$ & $26(9-35)$ & $38(18-56)$ \\
\hline
\end{tabular}

**p $<.01, * * * p<.001, n s=$ not significant; "Range" reflects minimum and maximum scores obtained 
$\underline{\text { Table 2: Bivariate Correlations for Demographic Variables and Outcomes }}$

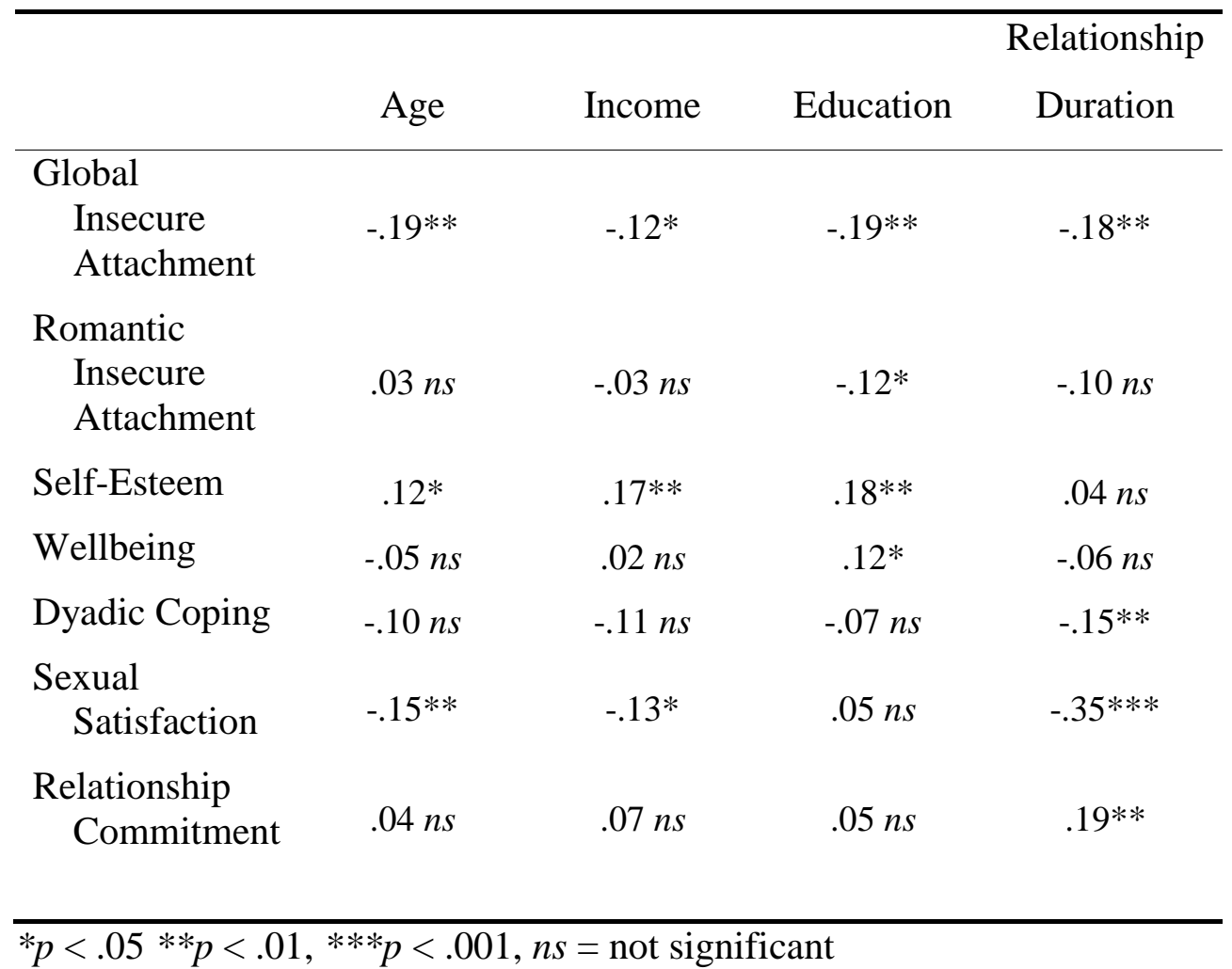


Table 3: Tests of Difference ${ }^{\ddagger}$ Between Correlates of Global and Romantic Attachment

\begin{tabular}{|c|c|c|c|c|c|c|c|c|c|}
\hline & Age & Income & Education & $\begin{array}{c}\text { Relationship } \\
\text { Duration }\end{array}$ & $\begin{array}{c}\text { Self- } \\
\text { Esteem }\end{array}$ & Wellbeing & $\begin{array}{c}\text { Sexual } \\
\text { Satisfaction }\end{array}$ & $\begin{array}{l}\text { Dyadic } \\
\text { Coping }\end{array}$ & $\begin{array}{l}\text { Relationship } \\
\text { Commitment }\end{array}$ \\
\hline Global & & & & & & & & & \\
\hline $\begin{array}{l}\text { Insecure } \\
\text { Attachment }\end{array}$ & $-.19 * *$ & $-.12 *$ & $-.19 * *$ & $-.18 * *$ & $-.50 * * *$ & $-.42 * * *$ & $-.31 * * *$ & -.10 & $-.17 * *$ \\
\hline $\begin{array}{l}\text { Romantic } \\
\text { Insecure } \\
\text { Attachment }\end{array}$ & .03 & -.03 & $-.12 *$ & -.10 & $-.36 * * *$ & $-.47 * * *$ & $-.45 * * *$ & $-.34 * * *$ & $-.36^{* * *}$ \\
\hline $\begin{array}{l}\text { Are the } \\
\text { correlations } \\
\text { significantly } \\
\text { different at } \\
p<.05 ?\end{array}$ & Yes & No & No & No & Yes & No & Yes & Yes & Yes \\
\hline
\end{tabular}

$* p<.05 * * p<.01, * * * p<.001$

tThe web-based statistical program cocor (Diedenhofen \& Musch, 2015) was used to compare these correlations (two-tailed test of dependent, overlapping data using $\alpha=.05$; confidence intervals $=95 \%)$. The following tests were included in each analysis: Pearson and Filon's (1898) z; Hotelling's (1940) t; Williams' (1959) t; Ilkin's (1967) z; Dunn and Clark's (1969) z; Hendrickson, Stanley, and Hills' (1970) modification of Williams' (1959) t; Steiger's (1980) modification of Dunn and Clark's (1969) z; Meng, Rosenthal, and Rubin's (1992) z; Hittner, May, and Silver's (2003) modification of Dunn and Clark's (1969) z; and Zou's (2007) confidence interval. For each case where cocor was used to compare correlations, these tests all produced equivalent results. Detailed statistics for each comparison are available upon request. 
Table 4: Multiple Regression

\begin{tabular}{|c|c|c|c|c|c|c|}
\hline & & $\begin{array}{c}\text { Self- } \\
\text { Esteem }\end{array}$ & Wellbeing & $\begin{array}{l}\text { Dyadic } \\
\text { Coping }\end{array}$ & $\begin{array}{c}\text { Sexual } \\
\text { Satisfaction }\end{array}$ & $\begin{array}{l}\text { Relationship } \\
\text { Commitment }\end{array}$ \\
\hline \multirow{3}{*}{ Age } & $B$ & $.003 n s$ & $-.05 n s$ & $-.02 n s$ & $-.01 n s$ & $.004 n s$ \\
\hline & $S E$ & .03 & .07 & .03 & .04 & .06 \\
\hline & $\beta$ & .005 & -.04 & -.04 & -.01 & .004 \\
\hline \multirow{3}{*}{ Income } & $B$ & $.46^{*}$ & $.26 n s$ & $-.08 n s$ & $.002 n s$ & $.09 n s$ \\
\hline & $S E$ & .21 & .44 & .21 & .25 & .38 \\
\hline & $\beta$ & .13 & .04 & -.02 & .000 & .02 \\
\hline \multirow{3}{*}{ Education } & $B$ & $.3 n s$ & $.34 n s$ & $-.47 *$ & $-.24 n s$ & $-.49 n s$ \\
\hline & $S E$ & .19 & .4 & .2 & .23 & .35 \\
\hline & $\beta$ & .08 & .04 & -.12 & .05 & -.08 \\
\hline \multirow{3}{*}{$\begin{array}{l}\text { Relation- } \\
\text { ship } \\
\text { Duration }\end{array}$} & $B$ & $-.38 *$ & $-1.01 * *$ & $-.63 * *$ & $-1.46 * * *$ & $.82 *$ \\
\hline & $S E$ & .18 & .38 & .18 & .22 & .32 \\
\hline & $\beta$ & -.18 & -.15 & -.19 & -.39 & .16 \\
\hline \multirow{4}{*}{$\begin{array}{l}\text { Insecure } \\
\text { Global } \\
\text { Attachment }\end{array}$} & $B$ & $-.18 * * *$ & $-.27 * * *$ & $-.09 * *$ & $.02 n s$ & $.01 n s$ \\
\hline & $95 \% C I$ & $-.23,-.13$ & $-.37,-.16$ & $-.14,-.03$ & $-.04, .08$ & $-.08, .10$ \\
\hline & $S E$ & .03 & .05 & .03 & .03 & .05 \\
\hline & $\beta$ & -.42 & -.29 & -.19 & .03 & .02 \\
\hline \multirow{4}{*}{$\begin{array}{l}\text { Insecure } \\
\text { Romantic } \\
\text { Attachment }\end{array}$} & $B$ & $-.08 * *$ & $-.34 * * *$ & $-.18 * * *$ & $-.22 * * *$ & $-.29 * * *$ \\
\hline & $95 \% C I$ & $-.14,-.03$ & $-.45,-.23$ & $-.23,-.12$ & $-.28,-.16$ & $-.38,-.19$ \\
\hline & $S E$ & .03 & .06 & .03 & .03 & .05 \\
\hline & $\beta$ & -.19 & -.36 & -.39 & -.41 & -.38 \\
\hline \multirow{3}{*}{$\begin{array}{l}\text { Insecure } \\
\text { Global x } \\
\text { Romantic } \\
\text { Attachment }\end{array}$} & $B$ & $.003 n s$ & $.004 n s$ & $-.002 n s$ & $.003 n s$ & $.02 n s$ \\
\hline & $S E$ & .002 & .004 & .002 & .002 & .003 \\
\hline & $\beta$ & .09 & .05 & -.06 & .06 & .09 \\
\hline
\end{tabular}

$* p<.05, * * p<.01, * * * p<.001, n s=$ not significant; items in italics represent controls 


\section{FIGURES}

Figure 1: Attachment activation (Mikulincer et al., 2003)

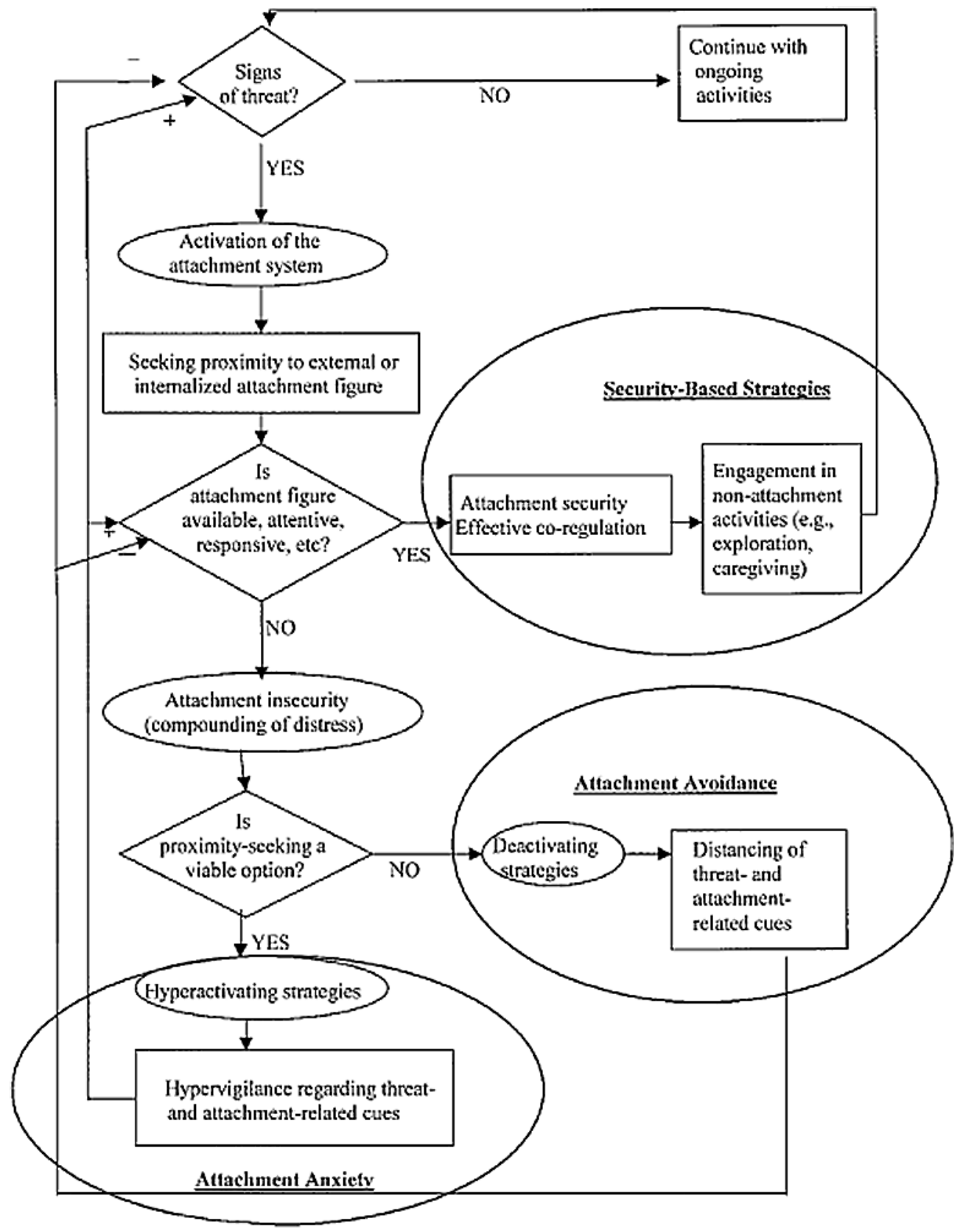


Figure 2: Potential Global x Romantic Interaction Effects

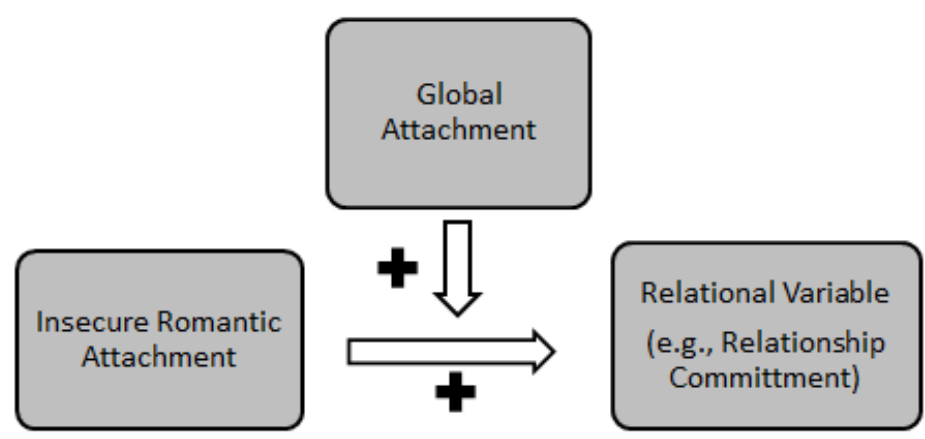

Secure Global Attachment may amplify Insecure Romantic Attachment.

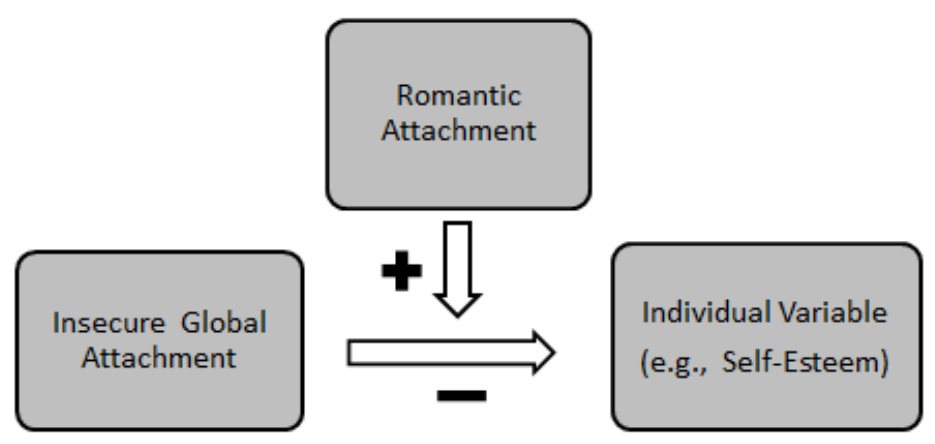

Secure Romantic Attachment may lessen Insecure Global Attachment. 


\section{APPENDICES}

\section{Appendix 1: Demographics}

\section{About the individual}

\section{Item}

1. What is your age?

2. Are you currently involved in a romantic relationship?

3. What is your gender?

4. What is your ethnicity?

5. What is your sexual orientation?

6. What is your income?

7. What is your level of education?

8. In what U.S. State, Commonwealth, or Territory do you live?

$2 \mathrm{a}$.What is your nationality/country of residence?
Answer Type

Open Field ${ }^{5}$

Yes or $\mathrm{No}^{6}$

Open Field

Open Field

Open Field

Multiple choice of income ranges

Multiple choice of

education categories

Dropdown List of

States

Open Field

\section{About the relationship}

\section{Item}

1. How long have you been in this romantic relationship?

2. How would you categorize the nature of your romantic relationship?

3. What is your partner's gender?

\section{Answer Type}

Multiple-choice of age ranges

Multiple-choice of relationship categories

Open Field

\footnotetext{
${ }^{5}$ Participants who are under age 18 will not proceed to the study questions.

${ }^{6}$ Participants who are not currently in a romantic relationship and who report that their relationship is "casually dating" will answer demographic questions only.
} 


\section{Appendix 2: Experiences in Close Relationships Scale - Short Form}

(Wei, Russell, Mallinckrodt, \& Vogel, 2007)

\section{Global Attachment Phrasing and Items}

[Think about the close relationships in your life, which may include friends, family, romantic partners, coworkers, and others. Please respond to each statement by indicating the extent to which the statement sounds like you, taking all of your relationships with those people into account.]

$$
\begin{aligned}
& 1=\text { Definitely like me } \\
& 2= \\
& 3= \\
& 4= \\
& 5= \\
& 6= \\
& 7=\text { Definitely NOT like me }
\end{aligned}
$$

\section{Scale Item}

1. I want to get close to those people, but I keep pulling back.

2. I am nervous when those people get too close to me.

3. I try to avoid getting too close to those people.

4. I usually discuss my problems and concerns with those people.

5. It helps to turn to those people times of need.

6. I turn to those people for many things, including comfort and reassurance.

7. I worry that those people won't care about me as much as I care about them.

8. My desire to be very close sometimes scares those people away.

9. I need a lot of reassurance that I am loved by those people.

10. I do not often worry about being abandoned by those people.

11. I find that those people don't want to get as close as I would like.

12. I get frustrated if those people are not available when I need them.

\section{Subscale}

Avoid

Avoid

Avoid

Avoid (rc)

Avoid (rc)

Avoid (rc)

Anxious

Anxious

Anxious

Anxious

(rc)

Anxious

Anxious 


\section{Romantic Attachment Phrasing and Items}

[Think about your current romantic relationship. If you have more than one romantic partner, pick one person to think about. Please respond to each statement by indicating the extent to which the statement sounds like you, thinking about that romantic partner.]

$$
\begin{aligned}
& 1=\quad \text { Definitely like me } \\
& 2= \\
& 3= \\
& 4= \\
& 8= \\
& 9= \\
& 10=\quad \text { Definitely NOT like me }
\end{aligned}
$$

\section{Scale Item}

1. I want to get close to my partner, but I keep pulling back.

2. I am nervous when my partner gets too close to me.

3. I try to avoid getting too close to my partner.

4. I usually discuss my problems and concerns with my partner.

5. It helps to turn to my romantic partner in times of need.

6. I turn to my partner for many things, including comfort and reassurance.

7. I worry that my partner won't care about me as much as I care about them.

8. My desire to be very close sometimes scares my partner away.

9. I need a lot of reassurance that I am loved by my partner.

10. I do not often worry about being abandoned by my partner.

11. I find that my partner doesn't want to get as close as I would like.

12. I get frustrated if my romantic partners is not available when I need them.

$(\mathrm{rc})=$ reverse coded

\section{Subscale}

Avoid

Avoid

Avoid

Avoid (rc)

Avoid (rc)

Avoid (rc)

Anxious

Anxious

Anxious

Anxious

(rc)

Anxious

Anxious 


\section{Perception of Partner Romantic Attachment Phrasing and Items}

[Think about your current romantic relationship. If you have more than one romantic partner, pick one person to think about. Please respond to each statement by indicating the extent to which the statement sounds like you, thinking about that romantic partner.]

$$
\begin{aligned}
& 1=\text { Definitely like me } \\
& 2= \\
& 3= \\
& 4= \\
& 5= \\
& 6= \\
& 7=\text { Definitely NOT like me }
\end{aligned}
$$

Scale Item

\section{Subscale}

13. My partner wants to get close to me, but they keep pulling back.

Avoid

14. My partner gets nervous when I get too close to them.

Avoid

15. My partner tries to avoid getting too close to me.

Avoid

16. My partner usually discusses their problems and concerns with me.

Avoid (rc)

17. My partner believes it helps to turn to me in times of need.

Avoid (rc)

18. My partner turns to me for many things, including comfort and reassurance.

Avoid (rc)

19. My partner worries that I won't care about them as much as they care about me.

Anxious

20. My partner believes that their desire to be very close sometimes scares me away.

Anxious

21. My partner needs a lot of reassurance that they are loved by me.

22. My partner does not often worry about being abandoned by me.

23. I believe my partner finds that I don't want to get as close as they would like.

Anxious

24. In general, my partner gets frustrated if their romantic partners are not available when they need them.

Anxious

$(\mathrm{rc})=$ reverse coded 


\section{Appendix 3: Rosenberg Self-Esteem Scale}

(Rosenberg, 1979)

Please record the appropriate answer for each item, depending on whether you Strongly agree, agree, disagree, or strongly disagree with it.

$1=$ Strongly agree

$2=$ Agree

$3=$ Disagree

$4=$ Strongly disagree

1. On the whole, I am satisfied with myself.

2. At times I think I am no good at all.

3. I feel that I have a number of good qualities.

4. I am able to do things as well as most other people.

5. I feel I do not have much to be proud of.

6. I certainly feel useless at times.

7. I feel that I'm a person of worth.

8. I wish I could have more respect for myself.

9. All in all, I am inclined to think that I am a failure.

10. I take a positive attitude toward myself. 


\section{Appendix 4: Schwartz Outcome Scale}

(Blais et al., 1999)

Below are 10 statements about you and your life that help us see how you feel you are doing. Please respond to each statement by circling the response number that best fits how you have generally been over the last seven days (1 week). There are no right or wrong responses, but is important that your response reflect how you feel you are doing. Please be sure to respond to each statement.

$$
\begin{aligned}
& 0=\text { Never } \\
& 1 \\
& 2 \\
& 3 \\
& 4 \\
& 5 \\
& 6 \\
& 7=\text { All the time }
\end{aligned}
$$

1. Given my current physical condition, I am satisfied with what I can do.

2. I have confidence in my ability to sustain important relationships.

3. I feel hopeful about my future.

4. I am often interested and excited about things in my life.

5. I am able to have fun.

6. I am generally satisfied with my psychological health.

7. I am able to forgive myself for failures.

8. My life is progressing according to my expectations.

9. I am able to handle conflicts with others.

10. I have peace of mind. 


\section{Appendix 5: Dyadic Coping Inventory}

(Bodenmann, 2008)

[Note: Subscales related to partner and combined actor-partner behavior were removed]

The following questions are designed to measure how you and your partner cope with stress. Please indicate the first response that you feel is appropriate. Please be as honest as possible. There are no wrong answers. Please respond to each item by marking how often that statement is true in your relationship. For each question, choose from the following alternatives:

$0=$ never

$1=$ almost never

$2=$ sometimes

$3=$ fairly often

$4=$ very often

$$
\begin{aligned}
& \mathrm{sc}=\text { stress communication } \\
& \mathrm{sb}=\text { supportive behaviors } \\
& \mathrm{nb}=\text { negative behaviors } \\
& \mathrm{dc}=\text { delegated coping }
\end{aligned}
$$

This section is about how you communicate your stress to your partner.

1. I let my partner know that I appreciate his/her practical support, advice, or help. (sc)

2. I ask my partner to do things for me when I have too much to do. (sc)

3. I show my partner through my behavior when I am not doing well or when I have problems. (sc)

4. I tell my partner openly how I feel and that I would appreciate his/her support. (sc)

This section is about what you do when your partner makes his/her stress known.

5. I show empathy and understanding to my partner. (sb)

6. I express to my partner that I am on his/her side. (sb)

7. I blame my partner for not coping well enough with stress. (nb)

8. I tell my partner that his/her stress is not that bad and help him/her to see the situation in a different light. (sb)

9. I listen to my partner and give him/her space and time to communicate what really bothers him/her. (sb)

10. I do not take my partner's stress seriously. (nb)

11. When my partner is stressed I tend to withdraw. (nb)

12. I provide support, but do so unwillingly and unmotivated because I think that he/she should cope with his/her problems on his/her own. (nb)

13. I take on things that my partner would normally do in order to help him/her out. (dc)

14. I try to analyze the situation together with my partner in an objective manner and help him/her to understand and change the problem. (sb)

15. When my partner feels he/she has too much to do, I help him/her out. (dc) 


\section{Permission to use the FDCT-N}

Guy Bodenmann <guy.bodenmann@psychologie.uzh.ch>

Mon, Nov 30, 2015 at 10:36 AM

To: Meg Manthos <meg@pdx.edu>

Dear Mrs. Manthos

Thanks for your mail and interest in the Dyadic Coping Inventory (DCI) that is the latest scale based on the former FDCT-N. I enclose the questionnaire and information on psychometrics. I also attach an English validation study conducted in the U.S. by professor Randall.

You can use this questionnaire for your study.

Best regards,

Guy Bodenmann

Prof. Dr. Guy Bodenmann

Universität Zürich

Psychologisches Institut

Lehrstuhl für Klinische Psychologie

(Kinder/Jugendliche \& Paare/Familien)

Binzmühlestrasse 14/Box 23

CH-8050 Zürich

www.paarlife.ch

www.pz.uzh.ch

3 attachments

Dyadic Coping Inventory (DCI; Bodenmann, 2008).pdf 118K

Dyadic Coping Inventory_Description_.pdf 40K

Randall et al. (2015). English DCI Validation_Current Psychology.pdf 704K 


\section{Appendix 6: Global Measure of Sexual Satisfaction}

(Lawrence \& Byers, 1998)

In general, how would you describe your sexual relationship with your partner? For each pair of words below, circle the number which best describes your sexual relationship.

1. Very Good 76

2. Very Pleasant

$$
76
$$

3. Very Positive

$7 \quad 6$

4. Very Satisfying

$7 \quad 6$

5. Very Valuable

7

5

54

43

3

2

Very Bad

Very Unpleasant

$\begin{array}{lll}5 & 4 & 3\end{array}$

2

1

$2 \begin{gathered}\text { Very Negative } \\ 1\end{gathered}$

$2 \begin{aligned} & \text { Very Unsatisfying } \\ & 1\end{aligned}$

$\begin{array}{llll}5 & 4 & 3\end{array}$

Worthless




\section{Appendix 7: Revised Commitment Inventory}

(Owen, Rhoades, Stanley, \& Markman, 2011)

Note: The below questions represent the dedication commitment subscale only.

$$
\begin{aligned}
& 1=\text { Strongly Agree } \\
& 2= \\
& 3= \\
& 4= \\
& 5= \\
& 6= \\
& 7=\text { Strongly Disagree }
\end{aligned}
$$

1. My relationship with my partner is more important to me than almost anything in my life.

2. I want this relationship to stay strong no matter what rough times we encounter.

3. I like to think of my partner and me more in terms of "us" and "we" than "me" and "him/her."

4. I think a lot about what it would be like to be married to (or dating) someone other than my partner.

5. My relationship with my partner is clearly part of my future life plans.

6. My career (or job, studies, homemaking, childrearing, etc.) is more important to me than my relationship with my partner.

7. I do not want to have a strong identity as a couple with my partner.

8. I may not want to be with my partner a few years from now. 


\author{
CURRICULUM VITAE \\ Megan Manthos \\ 4140 NE Crystal Springs Blvd \\ Portland, OR 97202 \\ 206-321-0510 \\ mmanthos@louisville.edu
}

\title{
Clinical Licensure
}

Licensed Psychological Associate

Kentucky State Board of Examiners of Psychology

License \#163913

Status: Active, non-practicing

\section{Education}

University of Louisville, Louisville, KY

current

Doctoral Candidate - Counseling Psychology

Dissertation Defense: July 15, 2016

M.Ed., University of Louisville, Louisville, KY

Master of Education in Counseling Psychology

B.S., University of Washington, Seattle, WA

2008

Bachelor of Science in Psychology

A.A., AIMS Community College, Greeley, CO

1996

Associate of Arts in Liberal Arts

\section{Clinical Hours}

Total anticipated by Aug 2016: 5700

As a practicum student: 1900 (930 direct)

As a Licensed Psychological Associate: 1800 (775 direct)

In-progress as a doctoral intern: 2000 (500 direct) 


\section{Clinical Experience}

Portland State University, Portland, OR Current

Doctoral Intern

Population: Urban university students

End date: 08/23/16

Green Line Wellness, PLLC, Louisville, KY

2014-2015

Licensed Psychological Associate

Population: Couples, adults, \& adolescents

Adult and adolescent transgender clients needing

psychological evaluation for hormonal./surgical transition

Survivors of Torture Recovery Center, Louisville, KY

Therapist Volunteer

Population: Recently relocated refugees with a history of

torture victimization

University of Louisville, Louisville, KY

Relationship \& Psychotherapy Lab

Therapist, Feedback-Informed Therapy Research Study

2013-2014

Therapist, Couple Psychotherapy Research Study

Population: Couples and adults

Central State Hospital, Louisville, KY

2012-2013

Psychology Trainee

Population: Severely mentally ill inpatients, voluntary and non-voluntary, forensic, high rate of active psychosis

Communicare, Inc., Radcliff, KY

2011-2012

Mental Health Intern

Population: Adults, adolescents, and children from

Impoverished communities in the rural south

University of Louisville, Louisville, KY

2010-2012

Facilitator, Prevention and Relationship Education

Population: Couples engaged in divorce prevention 


\section{Teaching Experience}

University of Louisville, Louisville, KY

Adjunct Faculty

ECPY 605 Human Development

Graduate Instructor

ECPY 607 Learning Theory \& Human Development

EDTP 107 Human Development \& Learning

Guest Lecturer: Integrative Couple Therapy

ECPY 621 Differential Diagnosis \& Treatment in Counseling

Graduate Teaching Assistant for Stephanie Budge, Ph.D.

ECPY 629 Techniques of Psychotherapy

ECPY 648 Intellectual Assessment

ECPY 663 Multicultural Issues in Counseling

\section{Additional Training}

American Association for Sexuality Educators, Counselors, and Therapists (AASECT): Certification in progress

Sexual Attitude Reassessment: Completed June 2016

World Professional Association for Transgender Health Mental Health Care (Chicago, IL)

Prevention and Relationship Education Program (PREP)

Facilitator Training (Orlando, FL)

\section{Employment}

\section{Portland State University Center for}

Student Health and Counseling, Portland, OR

Doctoral Intern

Green Line Wellness, PLLC, Louisville, KY

Licensed Psychological Associate

Central State Hospital, Louisville, KY

Psychology Trainee 
Communicare, Inc., Radcliff, KY

2011-2012

Mental Health Intern

University of Louisville, Louisville, KY

Dept. of Educational and Counseling Psychology,

Counseling, and College Student Personnel

Adjunct Faculty

2014-2015

Graduate Instructor

2014

Graduate Assistant

2012-2013

Graduate Fellow

2010-2012

Dept. of Middle and Secondary Education

Graduate Instructor

2013-2014

Women's Clinical Research Center, Seattle, WA

2008-2010

Recruitment \& Regulatory Coordinator

Assoc. in Rehabilitation \& Neuropsychology, Seattle, WA 2006-2008

Office Manager

Quorum Review IRB, Inc., Seattle, WA

2001-2005

Operations Manager

Quality Management Supervisor

Project Manager

Associate Project Manager

\section{Professional Memberships}

American Psychological Association

Division 17, Society of Counseling Psychology

Division 29, Society for the Advancement of Psychotherapy

Division 44, Society for the Psychological Study of Lesbian, Gay, Bisexual, and Transgender Issues

Washington State Psychological Association

American Association of Sexuality Educators, Counselors, and Therapists (AASECT)

Community-Academic Consortium for Research on Alternative Sexualities (CARAS)

Trans* Sexuality Training Advocacy Research (tstar) 


\section{Service \& Outreach}

Trans* Sexuality Training Advocacy Research (tstar) 2013-current

Active Member, Trainer, Consultant

http://www.tstarlab.com/

Survivors of Torture Recovery Center

2014-2015

Volunteer Therapist

UofL LGBT Health Care Provider Certificate Series

2014

Panel Member, "Providing LGBT-Competent Healthcare"

Archives of Sexual Behavior

2014

Peer Reviewer

\section{Journal of Social and Personal Relationships}

Peer Reviewer

University of Louisville Counseling Psychology Program

Program Development, Outpatient Clinic

\section{APA Division 44}

Research Award Application Reviewer

Maylon-Smith Scholarship Award

Bisexual Foundation Award

\section{Stan Frager Talk Radio Show (970 WGTK)}

Guest (Topic: Couple Relationships)

American Psychological Association of Graduate Students

$2010-2011$

Campus Representative, Advocacy Coordinating Team

\section{University of Louisville}

Faculty Liaison, Doctoral Student Organization

$2011-2012$

Cabinet Member, Counseling Psychology Program

$2010-2011$

Doctoral Student Organization

Member, Counseling Psychology Program Diversity

$2011-2012$

Committee

Proofreader for manuscripts accepted for publication

in Psychotherapy and Archives of Sexual Behavior

$2011-2012$ 


\section{Papers}

Dissertation: Global and Specific Attachment Patterns in Romantic Relationships: Distinct and Interactional Functions (Defense scheduled for July 15, 0216)

Shuck, B., Owen, J., Manthos, M., Quirk, K., \& Rhoades, G. (2016) Co-Workers with benefits: The influence of commitment uncertainty and status on employee engagement in romantic workplace relationships. Journal of Management Development, 35, 382-393.

Manthos, M., Owen, J., \& Fincham, F. D. (2014). A new perspective on hooking up among college students: Sexual behavior as a function of distinct groups. Journal of Social and Personal Relationships, 31, 815-829.

Owen, J., Manthos, M., \& Quirk, K. (2013). Dismantling study of prevention and relationship education program: The effects of a structured communication intervention. Journal of Family Psychology, 27, 336-341.

Owen, J., Fincham, F. D., \& Manthos, M. (2013). Friendships after a friends with benefits relationship: Deception, psychological functioning, and social connectedness. Archives of Sexual Behavior, 42, 1443-1449.

Owen, J., Quirk, K., \& Manthos, M. (2012) I get no respect: The relationship between betrayal trauma and romantic relationship functioning. Journal of Trauma \& Dissociation, 13, 175-189.

\section{Presentations}

Owen, J., Manthos, M., \& Quirk, K. (2013, October). Communication skills training: Dismantling study of PREP. Symposium at 47th Annual Convention of Association of Behavioral and Cognitive Therapies. Nashville, TN.

Owen, J., Strokoff, J., \& Manthos, M. (2013, October). Couple Therapy Workshop Level I: Introduction to Concepts and Skills (3.5 CE credits). Presented at the University of Louisville in Louisville, KY.

Manthos, M. (2013, July). Working with Trans* and Genderqueer-Identified Clients in an Inpatient Setting. Presented at Central State Hospital in Louisville, KY. 
Budge, S., Barr, S., Katz-Wise, S., Keller, B., \& Manthos, M. (2013, June). Incorporating positivity into psychotherapy. Presented at the Philadelphia TransHealth Conference in Philadelphia, PA.

Barr. S., Stahl, A., Manthos, M., \& Budge, S. (2012, November). "It means that there aren't rules, and you don't have to ascribe to a specific binary": A qualitative investigation of genderqueer identity. Presented at the IMPACT LGBTQ Health \& Wellness Conference, Chicago, IL.

Manthos, M., Quirk, K., \& Halford, T. (2012, March). Listen to me: The relational benefits of structured communication skills. In Jesse Owen (Discussant), Learning to love: Impacts of alliance and content in couples' therapy and relationship education. Symposium conducted at the Great Lakes Counseling Conference, Purdue University, Lafayette, IN.

Halford, T., Manthos, M., \& Quirk, K. (2012, March). The role of alliance with racial/ethnic minority couples in relationship education. In Jesse Owen (Discussant), Learning to love: Impacts of alliance and content in couples' therapy and relationship education. Symposium conducted at the Great Lakes Counseling Conference, Purdue University, Lafayette, IN.

Quirk, K., Halford, T., \& Manthos, M. (2012, March). Impact of relationship distress on the therapeutic alliance in couple therapy. In Jesse Owen (Discussant), Learning to love: Impacts of alliance and content in couples' therapy and relationship education. Symposium conducted at the Great Lakes Counseling Conference, Purdue University, Lafayette, IN.

Keller, B., Fox, R., Manthos, M., Shuck, B., \& Owen, J. (2012, March). Coworkers with benefits: Romance in the workplace. Presented at the Spring Research Conference, University of Louisville, Louisville, KY.

Owen, J., Manthos, M. (2011, November). Treating the commitment question: The couple therapy nobody talks about. In Integrative couples therapy. Symposium conducted at the Kentucky Psychological Association Annual Convention, Lexington, KY.

Manthos, M., Owen, J. (2011, August). Hooking Up: Sexual Self-Schema and Predictors of Casual Sex Behavior. Presented at the annual meeting of the American Psychological Association, Washington, D.C. 
Manthos, M., Moore, J., \& Quirk, K. (2011, April). Understanding clients' sexual selfschema: The role of SSS and hooking up. In Jesse Owen (Discussant), No strings attached: What counselors need to know about friends with benefits relationships and hooking up experiences. Symposium conducted at the Great Lakes Counseling Conference, University of Indiana, Bloomington, IN.

Quirk, K., Manthos, M., \& Moore, J. (2011, April). No strings attached: Friends with benefits \& deception. In Jesse Owen (Discussant), No strings attached: What counselors need to know about friends with benefits relationships and hooking up experiences. Symposium conducted at the Great Lakes Counseling Conference, University of Indiana, Bloomington, IN.

Moore, J., Quirk, K., \& Manthos, M. (2011, April). Can hooking up be good for you? In Jesse Owen (Discussant), No strings attached: What counselors need to know about friends with benefits relationships and hooking up experiences. Symposium conducted at the Great Lakes Counseling Conference, University of Indiana, Bloomington, IN.

Manthos, M., Schacht, R. L., \& George, W. H. (2007, August). Sex Differences in SexRelated Alcohol Expectancies and Sexual Sensation Seeking as Predictors of Condom Use. Presented at the annual meeting of the International Academy of Sex Research, Vancouver, B.C., Canada.

\section{Research Experience}

\section{University of Louisville}

Relationship \& Psychotherapy Lab (RAP Lab)

Principal Investigator: Jesse Owen, Ph.D.

Research Assistant Mentor

2011-2014

Project Development

2010-2014

Couple Therapy Project

2012-2014

Workplace Romance Project

2011-2014

Betrayal Trauma Project

2010-2012

Sexual Self-Schema Project

2010-2013

Prevention and Relationship Education Project

2010-2013

Friends With Benefits Project

2010-2011

\section{University of Louisville}

Trans* and Sexuality Teaching, Advocacy, and

Research Lab ( $T *$ STAR Lab)

Principal Investigator: Stephanie Budge, Ph.D. 
Transgender Partners \& Sexuality Project

2014-2015

Research Lab Management

2012-2013

Transgender Positive Experiences Project

2012-2013

Genderqueer Identity Survey

2012-2013

Transgender Identity Content Analysis 2013

Transgender Psychotherapy Project

2013

Transgender Youth Project

2013

\section{University of Washington}

\section{Department of Psychology}

Principal Investigators: William H. George, Ph.D.,

Kristen Lindgren, Ph.D.

REASONS Sexual Arousal \& Risk-Taking Project

2006-2008

Young Adults' Sexual Intent Perceptions

2005-2006

Women's Clinical Research Center

2008-2010

Recruitment \& Regulatory Coordinator

Principal Investigator: Robin Kroll, M.D., F.A.C.O.G.

Neurocrine: A Phase II, Randomized, Double-Blind, Placebo-Controlled Study to Assess the Efficacy and Safety of xxxx in Subjects with Endometriosis. 2009-2010

Teva: A multicenter, open-label study to evaluate the efficacy and safety of a combination oral contraceptive regimen $(\mathrm{xxxx})$ for the prevention of pregnancy in women. 2009-2010

Teva: A multicenter, open-label, randomized, controlled study to compare the effects on bone mineral density of xxxx and a 28-day cycle oral contraceptive regimen in healthy, postmenarchal, adolescent females. 2009-2010

Bayer: A Multicenter, Double-Blind, Randomized, Parallel-Group Study to Evaluate Cycle Control, Bleeding Pattern, Blood Pressure, Lipid and Carbohydrate Metabolism of the Transdermal Contraceptive Patch xxxx vs. an Oral Comparator Containing xxxx in a 21-Day Regimen for 7 Cycles in 400 Women. 2009-2010

Wyeth: A Double-Blind, Randomized, Placebo-and-Active-Controlled Efficacy and Safety Study of the Effects of xxxx on Endometrial Hyperplasia and Prevention of Osteoporosis in Postmenopausal Women. 2009-2010 
Duramed: A Multicenter, Open-Label, Randomized, Controlled Study to Compare the Effects on Bone Mineral Density of xxxx and a 28-day Cycle Oral Contraceptive Regimen in Healthy, Postmenarchal, Adolescent Females. 2009-2010

Bayer: A Multicenter, Open-Label, Uncontrolled Study to Investigate the Efficacy and Safety of the Transdermal Contraceptive Patch Containing xxxx in a 21-day Regimen for 13 Cycles in 1,650 Healthy Female Subjects. 2009-2010

Bayer: A Multicenter, Open-Label, Uncontrolled Study to Investigate the Impact of Weight and BMI on Inhibition of Ovulation of a Transdermal Patch Formulation Containing xxxx in Young Female Volunteers Stratified by BMI Over a Period of 3 Treatment Cycles. 2009-2010

Duramed: A Multicenter, Open-Label Study to Evaluate Ovarian Follicular Activity and Hormone Levels with the Oral Contraceptive Regimen xxxx. 2009-2010

Pfizer: A Phase II, 16 Week, Multicenter, Randomized, Double-Blind, PlaceboControlled, Parallel-Group Proof of Concept Study Evaluating the Efficacy and Safety of xxxx for the Treatment of Pain Associated with Endometriosis. 2008-2010.

Noven: A Phase 2, Exploratory, Eight-Week, Multicenter, Double-Blind, Randomized, Placebo-Controlled, Efficacy and Safety Study of xxxx in the Treatment of Vasomotor Symptoms Associated with Menopause. 2008-2009.

Takeda: Psychometric Evaluation and Validation of the Symptoms of xxxx Scale in Electronic Diary Format. 2008-2009.

Graceway: A Phase 3, Randomized, Double-blind, Placebo-controlled, Multicenter, Efficacy and Safety Study of xxxx in the Treatment of External Genital Warts. 20082009.

Wyeth: A Double-Blind, Randomized, Placebo-Controlled Study Assessing the Safety and Efficacy of xxxx for the Treatment of Vasomotor Symptoms Associated with Menopause. 2008-Current.

BioSante Pharmaceuticals: A Phase III, Randomized, Double-Blind, Placebo-Controlled, Multi-Center Study of the Safety and Efficacy of xxxx for the Treatment of Hypoactive Sexual Desire Disorder in Surgically Menopausal Women. 2008-2009. 
BioSante Pharmaceuticals: A Phase III, Randomized, Double-Blind, Placebo-Controlled, Multi-Center Study of the Long-Term Safety and Efficacy of Xxxx for the Treatment of Hypoactive Sexual Desire Disorder in Postmenopausal Women. 2008-2009.

Takeda Pharmaceuticals: Psychometric Evaluation and Validation of the xxxx Scale (xxxx) in Electronic Diary Format. 2008-2009.

Pfizer, Inc.: A Phase II, 16 Week, Multicenter, Randomized, Double Blind, PlaceboControlled, Parallel Group Proof of Concept Study Evaluating the Efficacy and Safety of xxxx for the Treatment of Pain Associated with Endometriosis. 2008-2009.

Noven Lifesciences: A Phase 2, Exploratory, Eight-Week, Multicenter, Double-Blind, Randomized, Placebo-Controlled, Efficacy and Safety Study of xxxx (xxxx) Capsules in the Treatment of Vasomotor Symptoms Associated with Menopause. 2008-2009.

Graceway Pharmaceuticals, LLC: A Phase III, Randomized, Double-blind, Placebocontrolled, Multicenter, Efficacy and Safety Study of xxxx in the Treatment of External Genital Warts. 2008.

Duramed Research, Inc.: A Multicenter, Randomized, Double-Blind, Parallel Group Study to Evaluate the Efficacy and Safety of Two Doses of xxxx Versus Placebo in Women with Overactive Bladder. 2008.

Wyeth Pharmaceuticals, Inc.: A Double-Blind, Randomized, Placebo-Controlled Study Assessing the Safety and Efficacy of xxxx for the Treatment of Vasomotor Symptoms Associated with Menopause. 2008.

Neurocrine BioSciences, Inc.: A Phase II, Randomized, Double-Blind, PlaceboControlled Study to Assess the Efficacy and Safety of xxxx Subjects with Endometriosis. 2008.

FemmePharma, Inc.: A Randomized, Double-Blind, Placebo-Controlled, Dose-Ranging Multicenter Evaluation of the Use of Topically Administered xxxx versus Placebo in Subjects with Pain Associated with Fibrocystic Breast Disease. 2008.

Bayer HealthCare Pharmaceuticals: A Multicenter, Double-Blind, Randomized, PlaceboControlled Study to Determine the Lowest Effective Dose of xxxx, xxxx, and xxxx for the Relief of Moderate to Severe Vasomotor Symptoms in Postmenopausal Women Over a Treatment Period of 12 Weeks. 2007-2008 


\section{References}

Jesse Owen, Ph.D.

Department Chair

Associate Professor

University of Denver

jesse.owen@du.edu

303-871-2482

Karen Ledbetter, Psy.D.

Licensed Psychologist

Assessment Coordinator

Portland State University

Center for Student Health \& Counseling

ledbetterk@pdx.edu

503-725-5319
Kelley Quirk, Ph.D.

Assistant Professor

Marriage and Family Program

Colorado State University

kelley.quirk@gmail.com

847-733-039

Marcy Hunt, Ph.D.

Licensed Psychologist

Counseling Services Director

Portland State University

Center for Student Health \& Counseling mhun2@pdx.edu

503-725-5194 